\title{
Ultimate limit state-based multi-objective optimum design technology for hull structural scantlings of merchant cargo ships
}

\author{
Dae Hun Kim ${ }^{1,2}$ and Jeom Kee Paik ${ }^{1,2,3^{*}}$ \\ ${ }^{1}$ Department of Naval Architecture and Ocean Engineering, Pusan National University, Busan \\ 46241, Korea \\ ${ }^{2}$ The Korea Ship and Offshore Research Institute (The Lloyd's Register Foundation Research \\ Centre of Excellence), Pusan National University, Busan 46241, Korea \\ ${ }^{3}$ Department of Mechanical Engineering, University College London, London WC1E 7JE, UK \\ *Corresponding author: J.K. Paik, (Tel) +82 51510 2429, (Fax) +82 51518 7687, \\ jeompaik@ pusan.ac.kr
}

\begin{abstract}
As the ultimate limit state is now a primary criterion for ship structural design, multi-objective optimization techniques for both minimizing weight and maximizing safety are routine practices in the structural design of naval ships as such techniques are critical for determining the structural weight needed to meet the functional requirements associated with naval armaments. However, a comparative approach is still used in the structural design of merchant cargo ships, based on measurements from existing as-built reference ships. This comparative approach obviously needs to be upgraded, because it requires more man-hours and causes more design errors than a fully automated design procedure. The comparative approach may also lead to inadequate design results, in which some structural members are too strong, and others barely satisfy the strength criteria, which can lead to catastrophic failures in some cases. The aim of this paper is to develop a fully automated methodology for the optimum design of hull structural scantlings for merchant cargo ships that are modelled by plate-shell finite elements. A full optimization technique with multi-objectives is applied for minimizing structural weight and maximizing structural safety, as per design constraints associated with the ultimate limit states of the plate panels, support members and hull girders. The developed procedure is applied to the hull structural scantlings of a very large crude oil carrier (VLCC), and this test demonstrates the procedure's capacity to meet the strength requirements of common structural rules. A
\end{abstract}


comparison between the new design and an as-built reference ship is made, confirming that the proposed procedure reduces the number of man-hours required by about $20 \%$, lightens the structural weight by $3 \%$ and improves the safety factors for the critical members.

Keywords: multi-objective optimum design, ultimate limit states, hull structural scantlings, plateshell finite element models, merchant cargo ships, very large crude oil carrier (VLCC)

\section{Introduction}

A number of challenges are evident in today's industry practices of ship structural design. In many cases, the scantlings of structural members are not fully optimized. Some members are too strong, and others are either too weak or barely strong enough. It is obvious that both weight minimization and safety maximization should be achieved simultaneously, and that the strength requirements must be met. The current industry practices take more man-hours for the design process, because they are not fully automated. Design errors are often found in the later stages of the design, and some errors remain undiscovered until the construction is complete, as the design work is primarily based on manual labor.

It is therefore advisable to fully automate the design process. An automated procedure is obviously beneficial, not only for minimizing the structural weight, but also for maximizing structural safety. The man-hours required for design work can be decreased, and design errors can be avoided. In fact, the benefits of full optimization technology for structural design have already been realized for naval ships, for which it is critical to design structural weight in association with the functional requirements of armament. It is certainly time for the merchant shipbuilding industry to adopt this technology, as cost reduction is now a major challenge in a difficult global economy.

Many useful contributions are available in the literature toward the development of full optimization technologies for ship structural design. Hughes (1983) is a pioneer of the rationally based structural design of ships, in which full optimization is applied to determine the best design variables to meet the strength requirements and minimize the structural weight. Hughes and Paik (2013) further advance the methods for determining load and strength requirements within the framework of the structural design, in association with the ultimate limit states of plate 
panels, support members and hull girders. McNatt et al. (2013) develop multi-objective optimization techniques, and they implement all of their proposed technologies into a practical ship structural design tool named MAESTRO (2016). This tool involves a computer code that is useful for the finite element modeling of an entire ship, or a partial ship. MARSTRO can perform finite element analysis, evaluate limit states and optimize structural features with the use of designer-specified objective functions.

Zanic (2013) develops design support methodology that is applicable for multi-criteria synthesis in the design of practical, complex ship structures. An efficient design procedure is developed that is capable of solving design problems with multiple objectives. A design support system combines an efficient model for analysis, evaluation and design-related objective decision-making by using modules that are available in MAESTRO and OCTOPUS (2012).

Turan (2007) proposes an integrated optimization method that incorporates a multi-criteria decision-making algorithm. This method includes a technique for indicating designer preferences by their similarity to ideal solutions (Hwang and Yoon 1981), a multi-objective genetic algorithm and a fast elitist non-dominated sorting genetic algorithm (Deb et al. 2000). The integrated optimization method is validated through its application to a Ro-Ro passenger ship design. Yang and Chen (2012) propose a knowledge-based engineering methodology for structural optimization design. This method re-uses domain knowledge in a new design, and provides rational advice for increasing the design efficiency due to improvements in the workflow of ship design. Pedersen (2013) proposes a systematic domain-independent method to design complex structures based on their hierarchical organization. This method enables effective and efficient design, numerical taxonomy to identify patterns of similarity in existing designs, technology diffusion to evaluate design processes, and multi-objective decisions regarding structures, design process, operational performance and cost.

A number of structural optimization technologies are also available that are based on design rules, such as the classification society's rules or the common structural rules (CSR) (IACS 2012). Jang and Shin (2006) propose a multi-objective optimization technique that follows one of the stochastic search methods. This technique identifies evaluation strategies, and applies them for the optimum design of CSR-based tankers, with consideration of the required freight rate. Payer (2013) elaborates the classification society's rules in terms of rationally based ship structural design, as applied to the load calculation and analysis of large container ships under 
global hull girder loads, impact loads and high-frequency hull girder loads. Na and Karr (2013) develops an efficient stiffness method for using three-dimensional beam modeling, based on consideration of the span point and the eccentric system line. The purpose of this method is to reduce the computing time required for analysis, and yet provide sufficient accuracy of results in the CSR-based ship optimization design stage.

Most of the contributions in the literature are related to the efforts to optimise simplified structures such as a 2-dimensional hull girder cross section or very coarse mesh finite element models. However, the real structural system is very complex in geometry and it is then partitioned into subsystems, the subsystems are further portioned into components, the components into parts, and so on. Such complex structures must be modelled using thousands nodes and elements that are corresponding to the structural design variables of the optimisation (Ma et al. 2016). An efficient and accurate approach is then needed to achieve the optimization of such a structure with complexity.

In this paper, a full optimization procedure for the structural design of merchant cargo ships is developed using plate-shell finite element models. Multiple objectives are considered, including the minimization of structural weight and the maximization of structural safety. Ultimate limit states of the plate panels, support members and hull girders are applied in terms of the strength criteria associated with design constraints. As the process confirms that the design rules, e.g., the CSR, are satisfied, the design can gain approval by the classification societies.

The developed procedure is then applied to an as-built very large crude oil carrier (VLCC) class double hull oil tanker, and a comparison is made between the resulting design and the asbuilt reference ship. This comparison confirms the benefits of the developed methodology in terms of structural weight saving, structural safety improvement and savings in man-hour costs.

\section{The Current Industry Practice versus the Developed Procedure}

An overview of the current industry practices for preliminary hull structural design is illustrated in Figure 1. The strength and acceptable safety of ship structures at both the member and the global hull girder levels are quantified through application of the prescriptive and the design verification requirements for a strength assessment that uses finite element analysis. The 
design procedure starts with the target structure of one central cargo hold (using a three-hold model), and then the procedure is extended to the neighboring hold structures.

For designing a large complex structure with the currently used procedure, a finite element analysis can be very demanding computationally. Despite steady advances in computing power, the expense of repetitious running of the analysis codes remains significant. As the updated designs are modified by manual labor, this structural design practice takes a great deal of time to complete, and such a practice increase the risk of design errors. In addition, the optimization process is not performed for all of the design variables at the same time, so that some structural members are designed for excessive scantlings, and others are designed for insufficient scantlings.

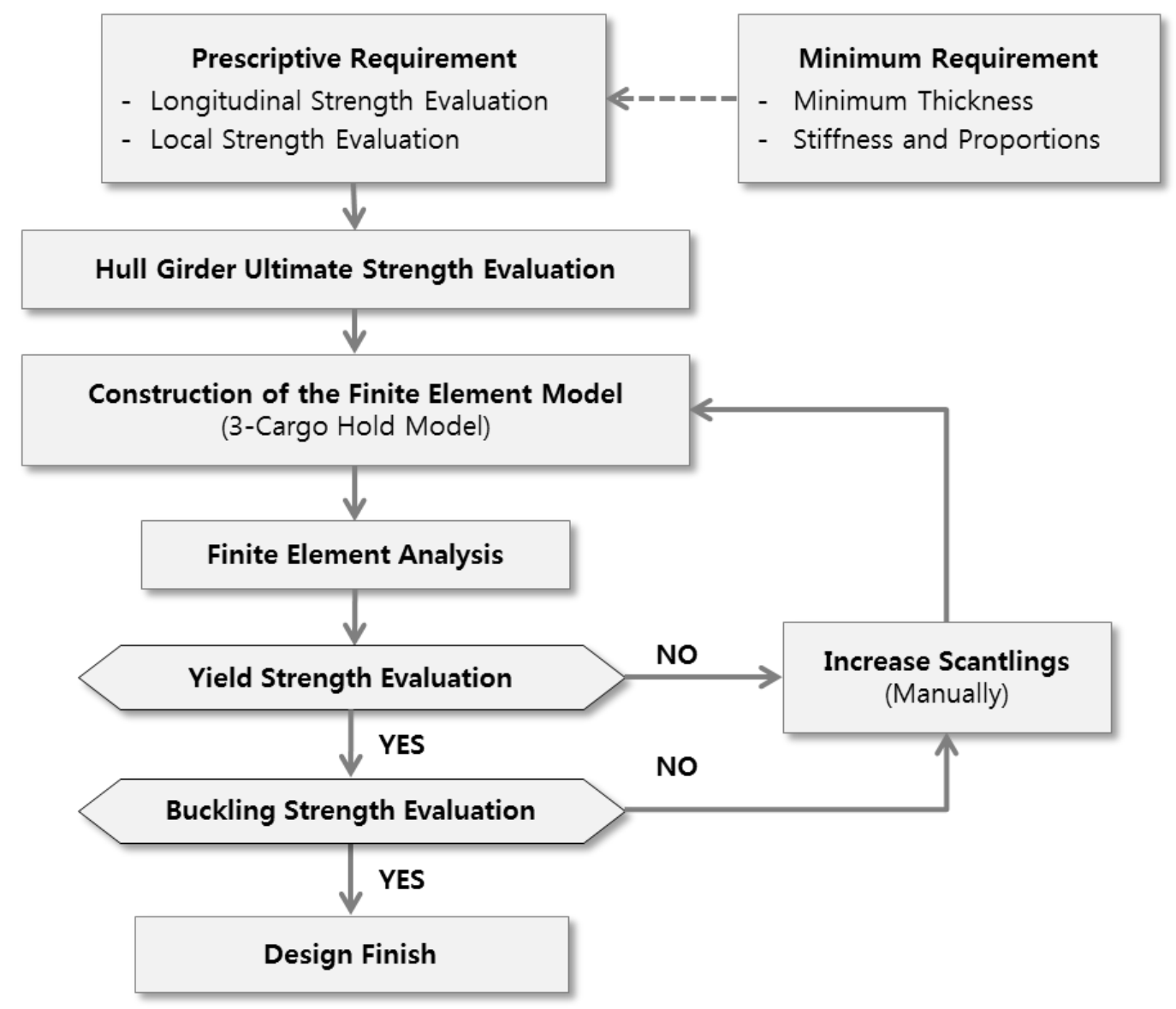

Fig. 1. The current industry practices for the design of preliminary hull structural scantlings (IACS 2012) 
To overcome these disadvantages of the current industry practices, a rationally based design procedure is needed. The proposed new procedure follows six steps. The overall design process is illustrated in Figure 2, which provides a flow chart of the full optimization procedure, as integrated into MAESTRO. The six main steps are as follows (Hughes and Paik 2013).

1. Construction of a full ship or partial length finite element model.

2. Calculation of static and dynamic loads that come from the ship's environment and from its motion.

3. Calculation of load effects from the environmental loads on the overall structure.

4. Calculation of limit values for the load effects, which produce or correspond to a limit state.

5. Formulation of reliability-based structural constraints, including partial safety factors and other constraints.

6. An optimization method that efficiently solves for the values of the design variables, yet yields maximum value on the measures of merit and satisfies all of the constraints.

Figure 3 shows a flowchart of the design procedure applied in this paper. Multiple objectives are considered, particularly the minimization of structural weight and the maximization of structural safety. In terms of plate-shell finite element modeling, the developed procedure makes two options available. The first option is to perform the structural optimization for an entire ship hull structure at once. The second option is to adopt a process similar to the current industry practices, using three cargo hold models, but with the full optimization of all design variables at the same time, even though only one cargo hold's structures are optimized in each design stage.

In the developed procedure the MAESTRO program is applied, into which the finite element models developed by other commercial softwares can be seamlessly imported. In the optimization process, the ultimate strength evaluations are quantified by ALPS/ULSAP (2016) for the plate panels and support members, and the modified Paik-Mansour method (Paik et al., 2012) is used for the hull girders. The hull girder progressive collapse strength is also quantified by ALPS/HULL (2016) to confirm the adequacy of the hull girder collapse based safety, after the optimization process is completed. The completed optimization results are also checked to determine whether the classification society rules are satisfied and the design can be approved. 


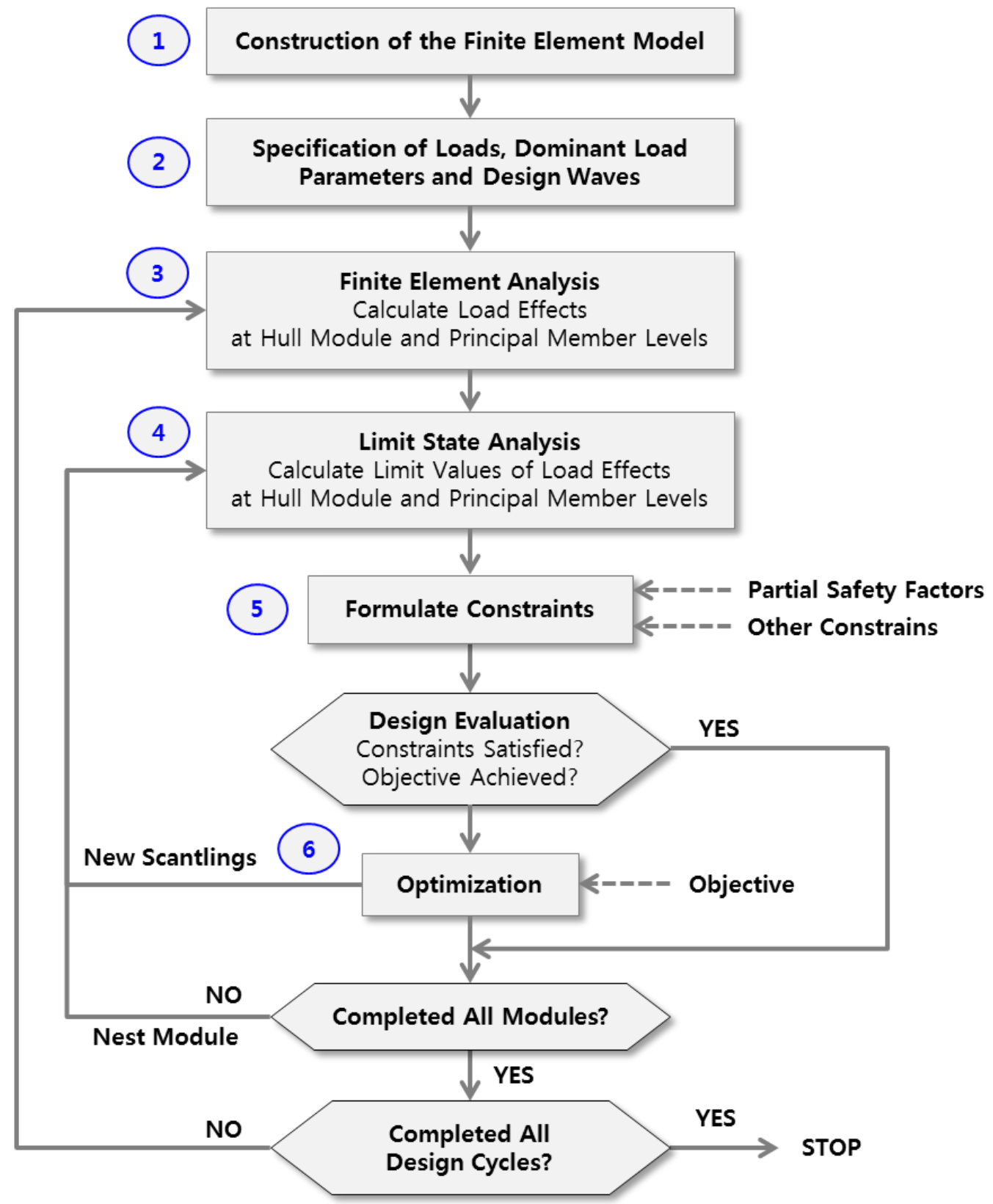

Fig. 2. Rationally based ship structural design (Hughes and Paik 2013) 


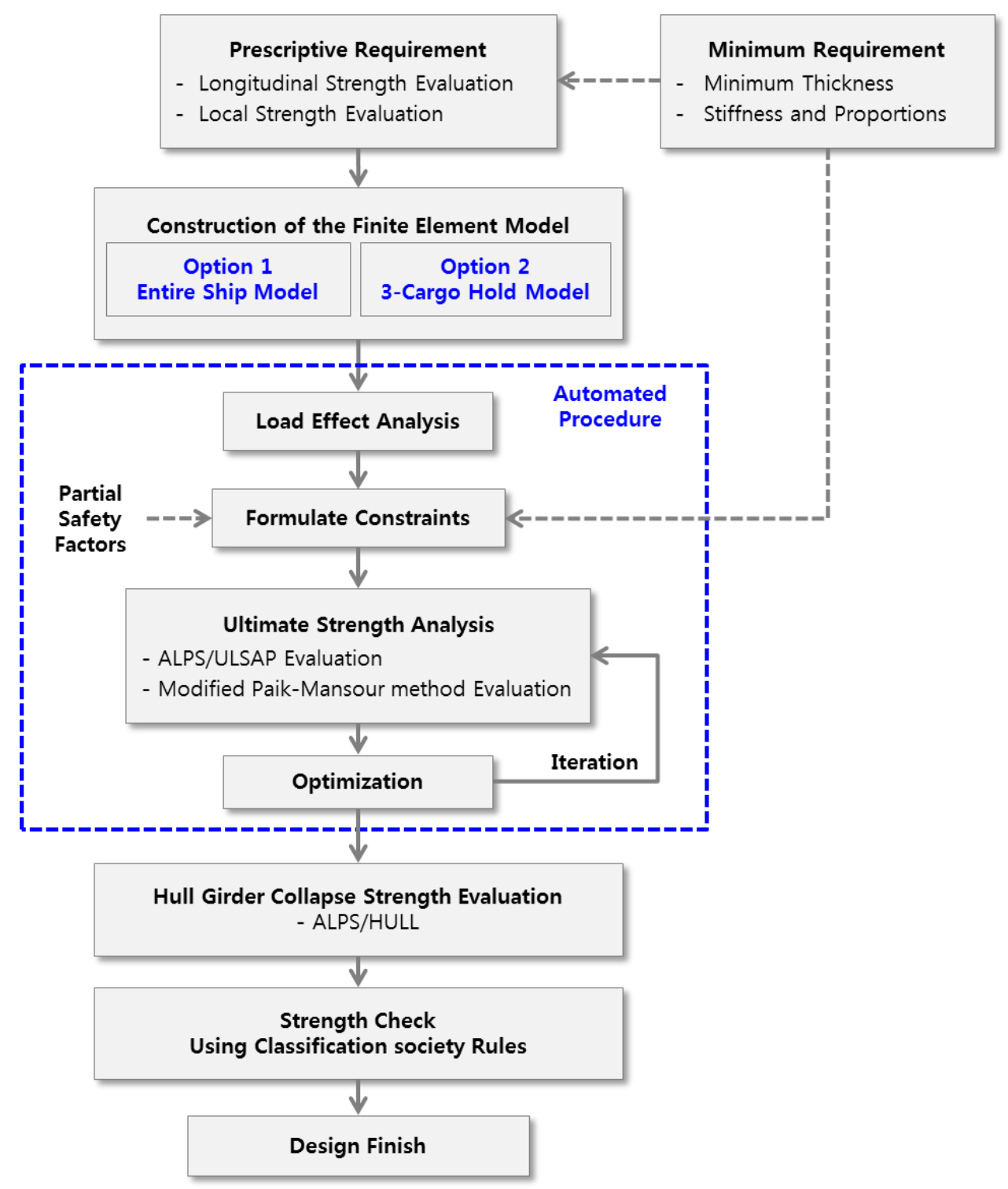

Fig. 3. The developed procedure for the preliminary hull structural scantlings, as considered in this paper

\section{Design Variables and Multi-Objective Functions}

In the optimization process, the design variables can be the scantlings of longitudinal plate panels, the longitudinal stiffeners or the primary support members, such as the longitudinal girders and transverse frames shown in Figure 4. The spacing of the longitudinal stiffeners and primary support members can also be design variables. In reality, the spacing of support members is fixed in advance, as per the requirements of cargo configuration and capacity. The 
actual optimization is usually undertaken for the scantlings of plate panels and of small or strong support members.

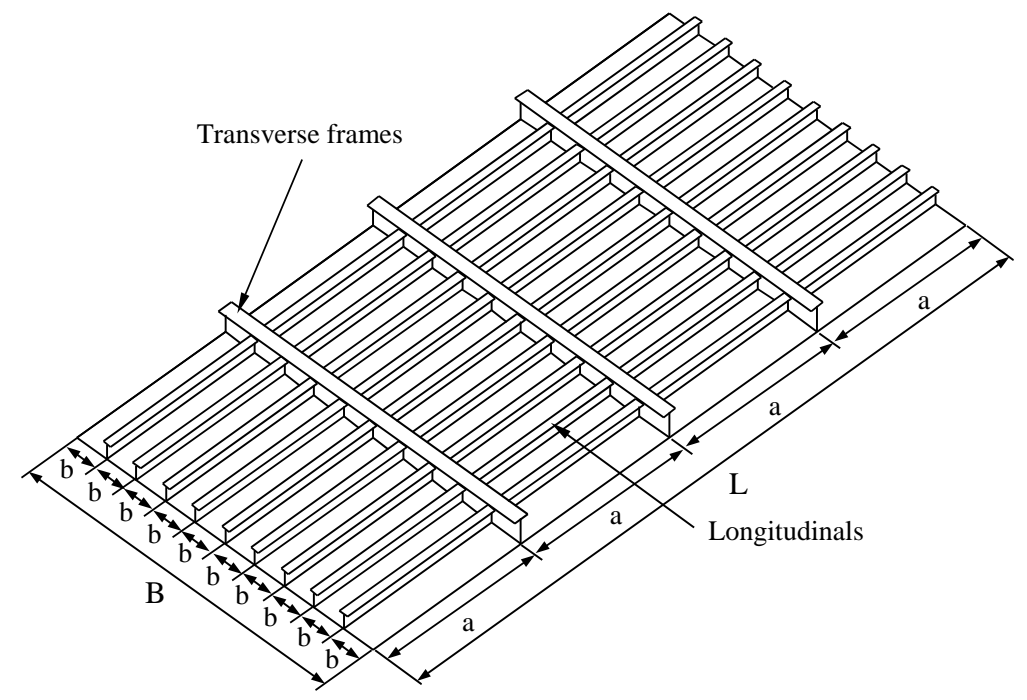

(a)
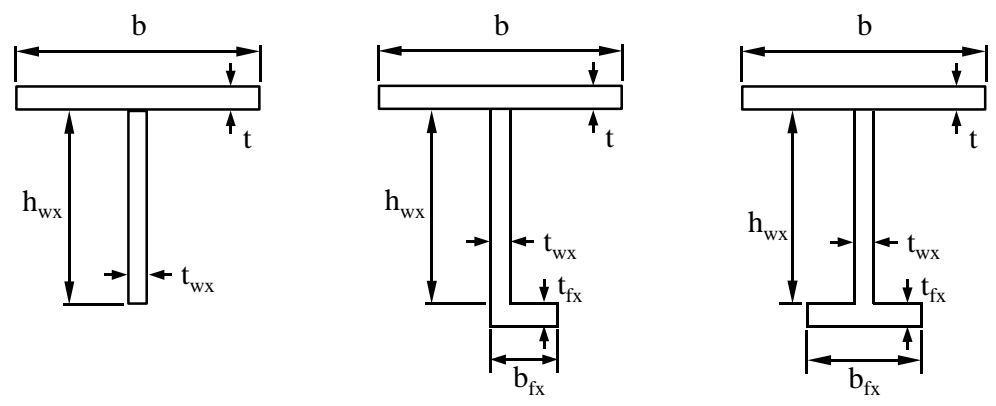

(b)
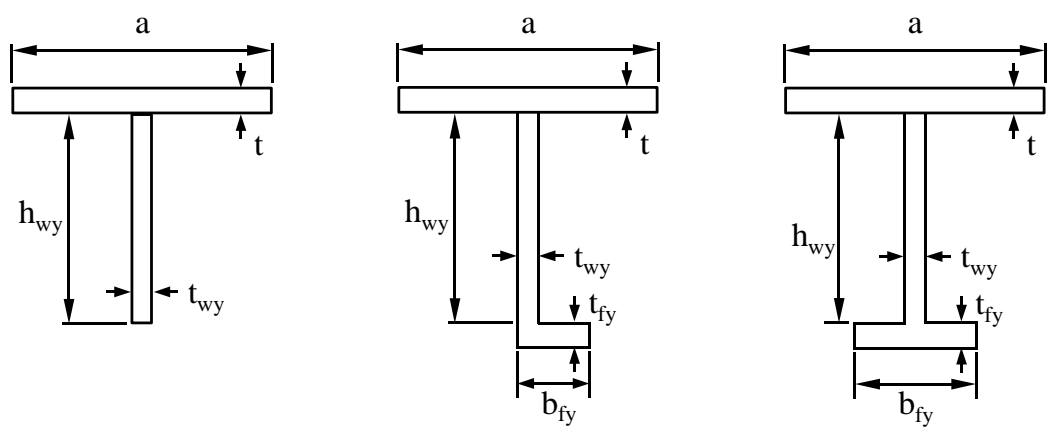

(c)

Fig. 4. (a) A stiffened plate structure, (b) Typical cross-section types of longitudinal support members, (c) Typical cross-section types of transverse support members (Paik and Thayamballi 2003) 
In the present paper, the structural optimization with multi-objective functions is performed by the Pareto method (Cayzak and Jaszkiewicz 1998, Ulungu et al. 1999, Jin and Sendhoff 2008), while the Bayesian approach is also known as a useful method for multi-objective optimization (Laummans and Ocenasek 2002, Subin et al. 2012).

The optimization process of the developed procedure considers three objective functions, namely structural weight $(W)$, labor cost $(C)$ and structural safety $(\eta)$, which are all functions of the design variables. The structural weight $(W)$ is a primary element of building cost that needs to be minimized. The labor cost $(C)$ represents design time and man-hours that should also be minimized. The structural safety $(\eta)$ is a safety measure, representing the adequacy of structural members, and this function needs to be maximized.

The objective functions can be formulated as follows:

$$
\begin{gathered}
\min \left(z_{1}\right)=\frac{W}{W_{o}} \\
\max \left(\frac{1}{z_{2}}\right)=\frac{\eta}{\eta_{o}} \text { or } \min \left(z_{2}\right)=\frac{\eta_{o}}{\eta} \\
\min \left(z_{3}\right)=\frac{C}{C_{o}}
\end{gathered}
$$

where $W_{o}, C_{o}$ and $\eta_{o}$ are the nominal initial design values of the structural weight, labor cost and safety measure, respectively. $z_{1}, z_{2}$ and $z_{3}$ are the normalized objective functions. It is noted that a reverse function, $z_{2}$, of structural safety is considered, and therefore this function must be minimized, to maximize the structural safety.

To satisfy all of the multi-objective functions, an aggregated energy function, $E$, is now established in association with simulated annealing method as follows:

$$
E=\lambda_{1} \frac{W}{W_{o}}+\lambda_{2} \frac{C}{C_{o}}+\lambda_{3} \frac{\eta_{o}}{\eta}+\sum_{i=1}^{m} c_{i} g_{i}(x)
$$

where $\lambda_{1}, \lambda_{2}$ and $\lambda_{3}$ are the weighting coefficients representing the relative importance of the objective functions for structural weight $W$, labor cost $C$ and structural safety $\eta$, respectively. It 
is usually assumed that the sum of the weighting coefficients is $1 . g_{i}(x)$ is the constraint penalty function with respect to solution vector $x$, and $c_{i}$ is the coefficient of the penalty function. $c_{i}$ is 0 if the design variables satisfy the constraints, and 1 if they violate the constraints. $m$ is the total number of penalty functions.

\section{Finite Element Modeling and Analysis}

\subsection{Extent of the analysis}

The developed procedure can accommodate two options in terms of finite element modeling, as mentioned in Chapter 2. The first option is to perform the structural optimization for all three cargo holds at the same time, i.e., the mid-ship, aft and forward cargo hold regions. This approach requires making a structural model of the entire ship. For the best results, the optimization should be performed using an entire ship model.

The second option for making a three-cargo-hold model is to perform the structural optimization for only one cargo hold, but to do so with the full optimization of all design variables. The results of this analysis are then extended to the mid-cargo hold region. For this paper's structural evaluation, each region is defined as in Figure 5.

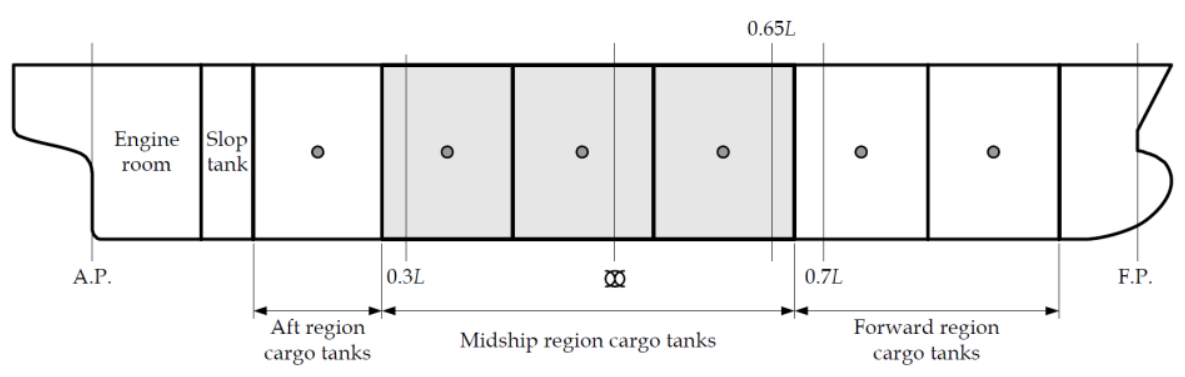

Fig. 5. Definition of the cargo hold regions for finite element analysis (IACS, 2012)

\subsection{MAESTRO finite element models}

For finite element models, all of the structural members, e.g., the main longitudinal and transverse structural elements, are basically modeled according to design rules. These elements 
include the inner and outer shell, the double-bottom floor and girder system, the transverse and vertical web frames, the stringers, and the transverse and longitudinal bulkhead structures.

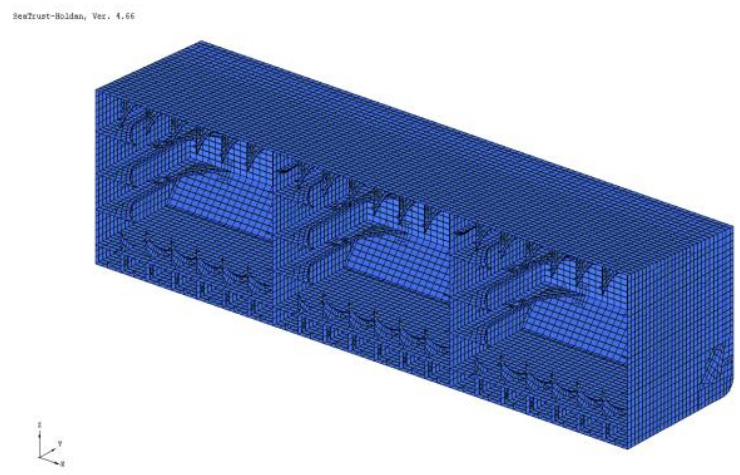

(a) Suezmax class tanker

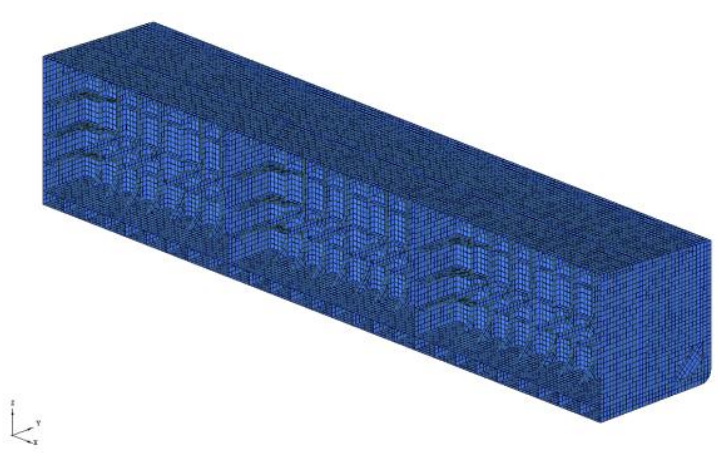

(b) VLCC class tanker

Fig. 6. Typical cargo tank models for tankers (showing only the port sides of the full breadth models)
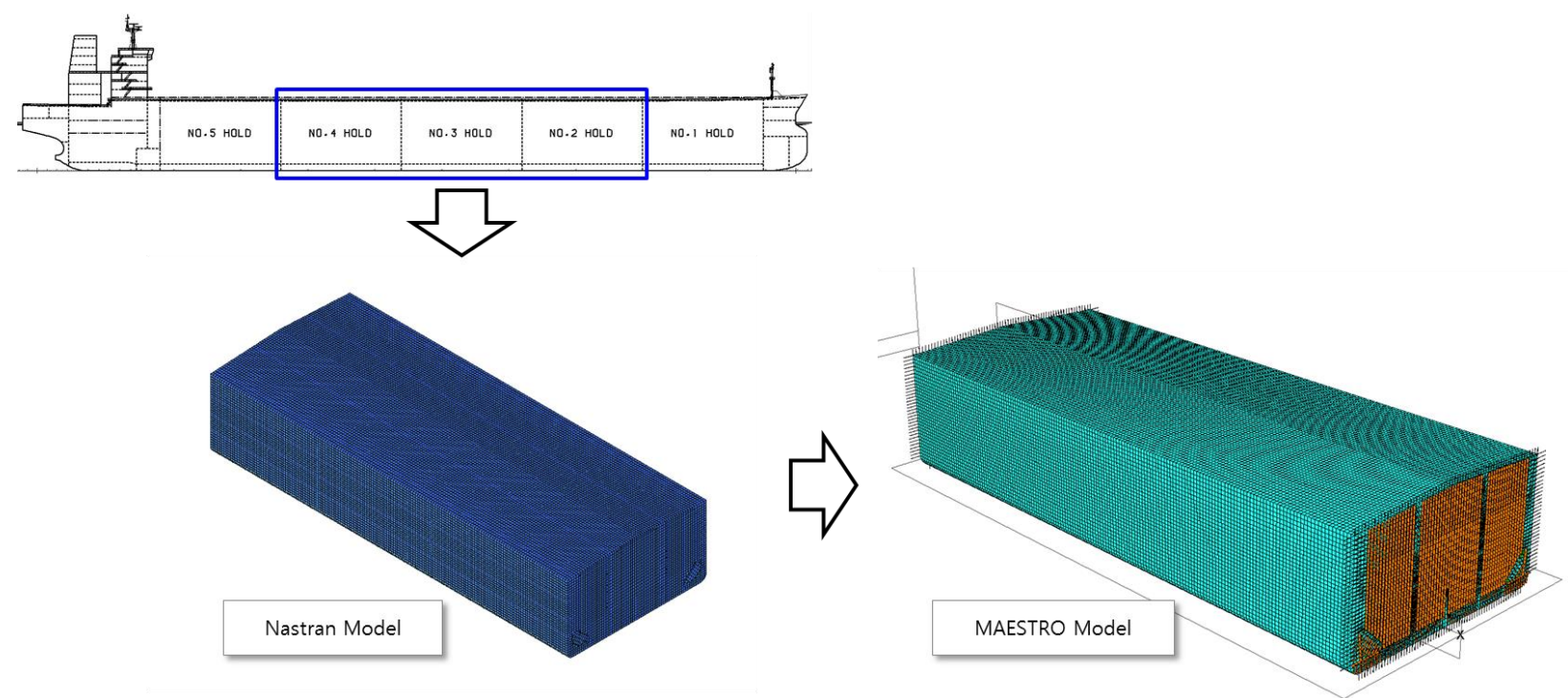

Fig. 7. Illustrative example of three-hold finite element model for a mid-ship cargo tank of a VLCC

The mesh of the finite element models needs to follow the stiffening system of the structure as far as is practical, and it needs to represent the actual plate panels between the stiffeners. The aspect ratio of the plate elements is, in general, not to exceed three. The use of triangular plate 
elements should be kept to a minimum. Where possible, the aspect ratios of plate elements in those areas where high stresses or high stress gradients are likely are to be kept close to 1, and the use of triangular elements is to be avoided. Typical finite element models representing threecargo-hold models are shown in Figure 6.

Finite element modeling can be performed with any kind of commercial software. For example, the Nastran-based software can be modified by manual labor and enabled to use a variety of modeling techniques, such as the three-dimensional modeling system for hull structure developed by Roh and Lee (2006). The completed finite element modeling, including all of the boundary and loading conditions, is performed using some kind of commercial finite element software that can be directly imported into MAESTRO for the developed procedure, as shown in Figure 7.

\subsection{Loading conditions}

All simultaneously acting hull girder and environmental loads are to be applied in the model. The combinations of the ship's static and dynamic loads, which are likely to impose the most conservative loads on the hull structure, are investigated in the structural analysis. For an entire ship hull structure, Ma et al. (2013) propose a practical method for balancing the loads in finite element models, while matching the hull girder sectional forces and moments. This method is both flexible and easy to implement.

If the analysis is not performed using an entire model, the loads, including the hull girder loads and the physical restraints, are imposed at the ends of the finite element models. In the case of tankers, the design rule-based load cases in the structural analysis are used as in the standard load cases given in Table 1 , and in accordance with CSR.

For design load combinations, the numbers of dynamic load cases that must be investigated for each loading pattern are indicated by the case numbers specified for that loading pattern. Each design load case consists of static loads (as described by the loading pattern), the ship's draft, the hull girder's still water bending moment, the shear force specified and the dynamic loads (as defined in Table 2) for each dynamic load case number. 
Table 1. Load cases for tankers with two oil-tight longitudinal bulkheads (IACS 2012)

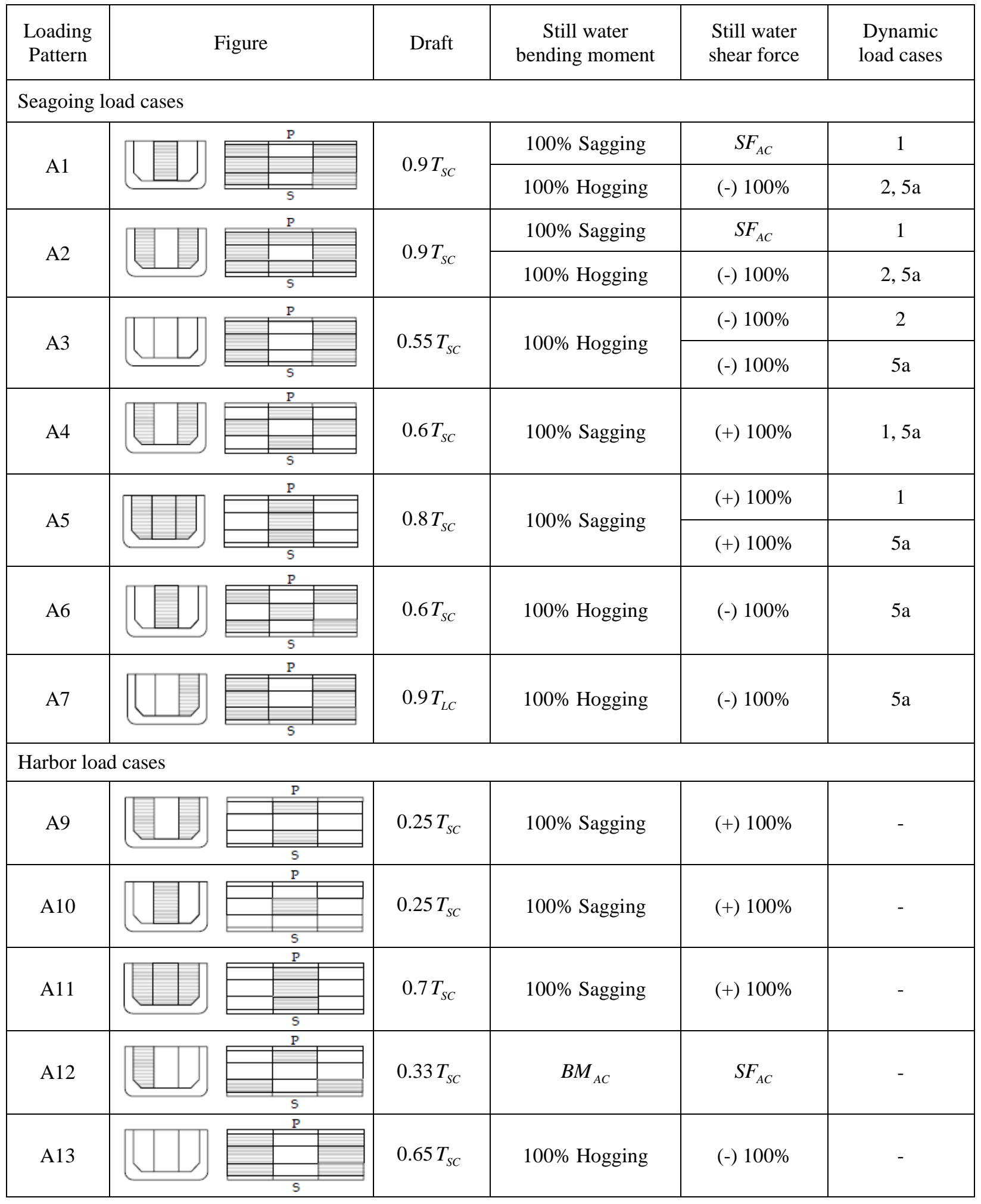




\begin{tabular}{|l}
\hline A14 \\
\hline Where \\
$T_{S C}$ is the scantling draft; \\
$T_{L C}$ is the draft in the loading condition being considered; \\
$B M_{A C}$ is the actual bending moment that results from the application of static and dynamic local loads; and \\
$S F_{A C}$ is the actual shear force that results from the application of static and dynamic local loads.
\end{tabular}

Table 2. Dynamic load combination factors (IACS 2012)

\begin{tabular}{|c|c|c|c|c|}
\hline \multicolumn{2}{|c|}{ Wave direction } & \multicolumn{2}{|c|}{ Head sea } & \multirow{2}{*}{$\begin{array}{c}\text { Beam sea } \\
\text { Vertical } \\
\text { accelerations }\end{array}$} \\
\hline \multicolumn{2}{|c|}{ Maximum response } & $\begin{array}{l}\text { Bending } \\
\text { moment } \\
\text { (sagging) }\end{array}$ & $\begin{array}{c}\text { Bending } \\
\text { moment } \\
\text { (hogging) }\end{array}$ & \\
\hline \multicolumn{2}{|c|}{ Dynamic load case } & 1 & 2 & $5 \mathrm{a}$ \\
\hline \multirow{2}{*}{ Global loads } & Wave bending moment & -1.0 & 1.0 & 0.0 \\
\hline & Wave shear force & 1.0 & -1.0 & 0.0 \\
\hline \multirow{3}{*}{ Accelerations } & Vertical direction & 0.5 & -0.5 & 1.0 \\
\hline & Transverse direction & 0.0 & 0.0 & -0.6 \\
\hline & Longitudinal direction & -0.6 & 0.6 & -0.5 \\
\hline \multirow{3}{*}{$\begin{array}{l}\text { Dynamic wave pressure } \\
\text { for port side }\end{array}$} & Pressure at waterline & -0.3 & 0.3 & 1.0 \\
\hline & Pressure at bilge & -0.3 & 0.3 & 1.0 \\
\hline & Pressure at centerline & -0.7 & 0.7 & 0.9 \\
\hline \multirow{3}{*}{$\begin{array}{l}\text { Dynamic wave pressure } \\
\text { for starboard side }\end{array}$} & Pressure at waterline & -0.3 & 0.3 & 0.4 \\
\hline & Pressure at bilge & -0.3 & 0.3 & 0.4 \\
\hline & Pressure at centerline & -0.7 & 0.7 & 0.9 \\
\hline
\end{tabular}




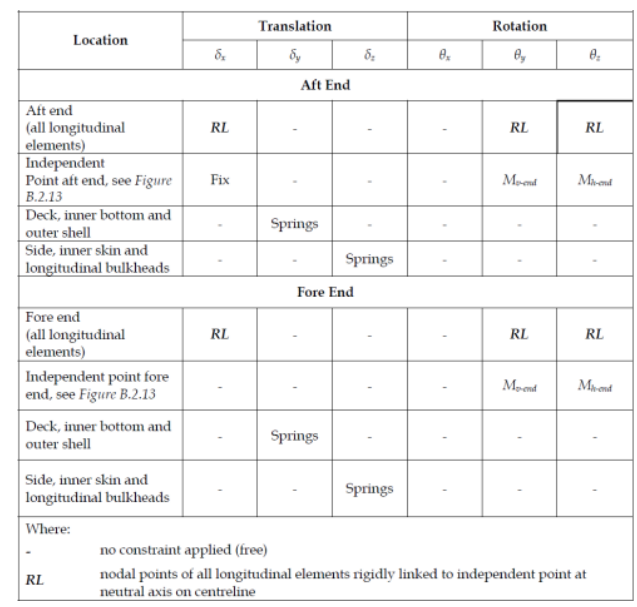

(a) Boundary Constraints

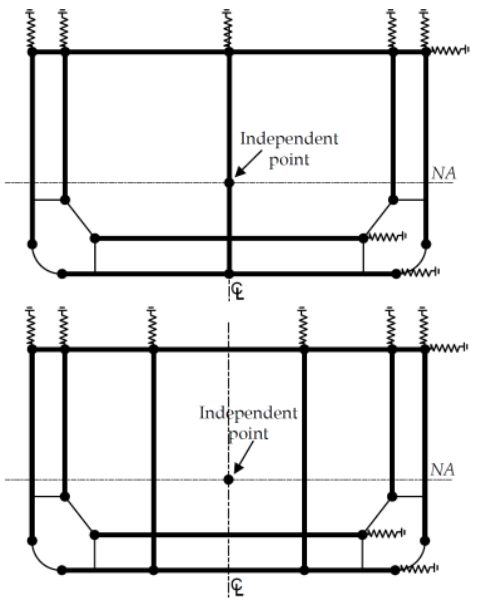

(b) Spring Constraints

Fig. 8. Boundary conditions at the model ends for finite element analysis (IACS 2012)

\subsection{Boundary conditions}

The boundary conditions for the entire ship models are automatically applied in MAESTRO, according to balancing of the loads. The boundary conditions for cut-models, e.g., three-hold models, can be defined using the hull sectional properties in MAESTRO, or they can be manually defined in accordance with guidance from design rules.

For tankers, CSR require that the boundary conditions be applied at the ends of the cargo tank model, and the spring elements with stiffness in the transverse and vertical directions should be applied to the grid points along the transverse and the vertical parts, as shown in Figure 8 .

For the individual spring elements of each structural member, their stiffness $(c)$ must be applied at each end of the cargo tank model is given by

$$
c=\left(\frac{E}{1+v}\right) \frac{A_{s}}{n l_{t k}}=0.77 \frac{E A_{s}}{n l_{t k}}(N / \mathrm{mm})
$$

where $A_{s}, v, 1_{t k}, E$ and $n$ are the shearing area (indicated in Figure 9), the Poisson's ratio of the material, the length of the cargo tank between bulkheads, the modulus of elasticity and the number of nodal points to which the spring elements are applied to the structural member. 


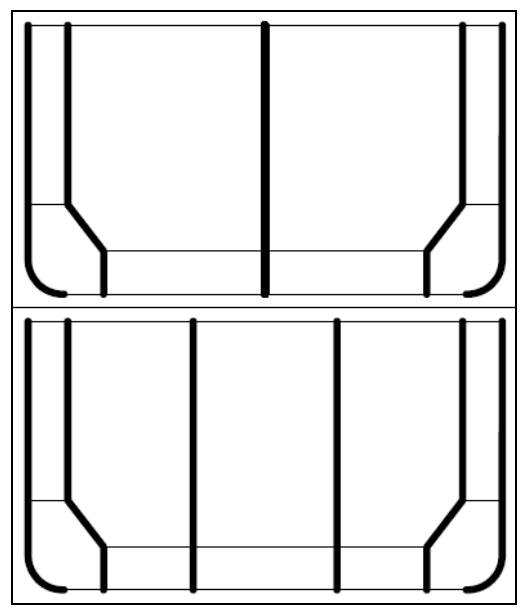

(a) Vertical springs

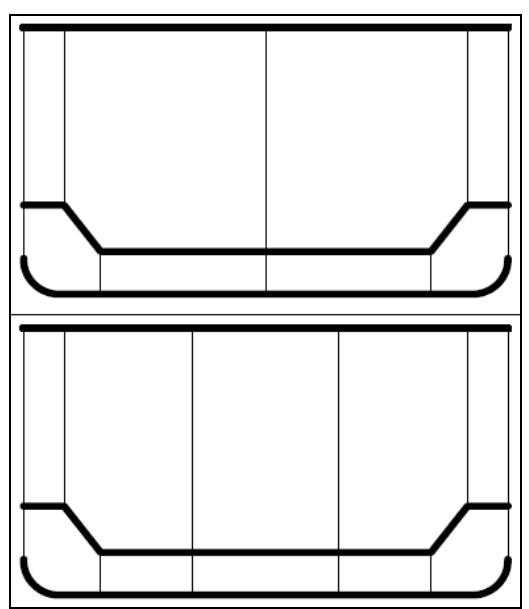

(b) Horizontal springs

Fig. 9. Shear areas to be considered for the calculation of spring stiffness (IACS 2012)

\subsection{Load effect analysis}

Based on the loading and boundary conditions of the finite element models described above, the load effect analysis is performed. Load effect analysis considers the responses, e.g., the bending moment, deflection and stress caused by all types of loading conditions on the structural modeling.

As a program for rationally based design, MAESTRO conducts the load-effect and the finiteelement analyses for calculating the load effects $(Q)$. MAESTRO also conducts the limit state analysis by examining all relevant types of failure, and it calculates the limit value of the load effects $\left(Q_{L}\right)$ for each specific structural member for all load cases. This program then searches the values of the load effects and the limit values of the load effects to find and use the currently worst combinations of these two quantities.

The program makes a note of the corresponding lowest values of the margin of safety for each limit state, and the location and load case where each lowest value occurs. Figure 10 illustrates the probability distributions of the load effect $(Q)$ and the limit value of the load effect $\left(Q_{L}\right)$, which show that even though $Q_{L}$ is well above the $Q$, there is some overlap of the curves, and hence some possibility of failure. 


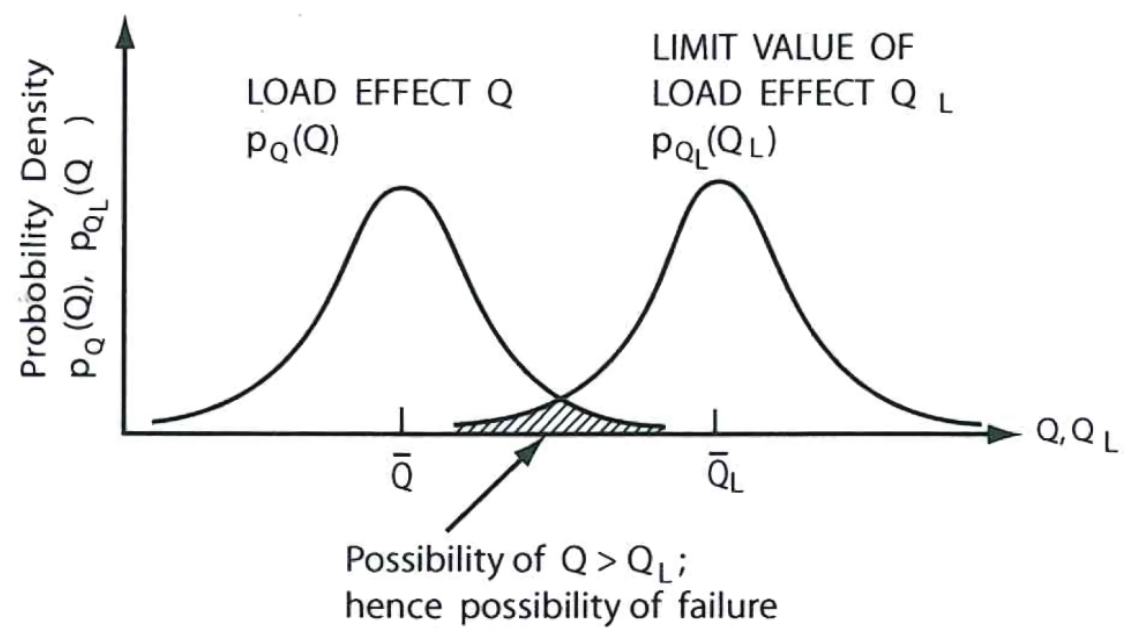

Fig. 10. Probability distributions of the load effect and the limit value of load effect (Hughes and Paik 2013)

\section{Ultimate Limit State Analysis}

\subsection{Partial safety factor-based design criterion}

As safety is one of the main design constraints in rationally based structural design, the safety of the structures is formulated in terms of partial safety factors. This formulation accounts for all of the uncertainties that affect the determination of the design variables, and the values of these uncertainties are based on the results of load effect analysis.

Partial safety factors are essential to enable accounting for different levels of safety and the degrees of seriousness of each particular limit state in regard to safety and serviceability. Such assessment is done through taking any special circumstances into account. In other words, this simple and explicit method adjusts the separation between the curves of the characteristic load effects $\left(Q_{c}\right)$ and the limit values of the characteristic load effects $\left(Q_{L, c}\right)$ to account for the degrees of seriousness for the particular types of failure that are being considered. The number of partial safety factors depends on the type of structure, and on what level of specification is preferred. Sometimes these safety factors are further subdivided for greater precision or consistency.

In the partial safety factor method, the strength constraints take the form of

$$
\gamma_{S 1} \gamma_{S 2} \gamma_{Q} Q_{c} \leq Q_{L, c} / \gamma_{L}
$$


where $\gamma_{S 1}$ and $\gamma_{S 2}$ are the load factors that account for the level of safety and serviceability for the type of failure under consideration. The $\gamma_{Q}$ is the load factor for the approximate uncertainties in the loads and the load effects, including the discrepancy between the structure's actual load effect and the value predicted by load effect analysis. The total load factor is simply defined by the product of these three partial load factors.

$$
\gamma_{\text {load }}=\gamma_{S 1} \gamma_{S 2} \gamma_{Q}
$$

The variable $\gamma_{L}$, which is called a limit value reduction factor (or a usage factor) indicates the approximate uncertainties in the estimated limit value. This situation is illustrated in Figure 11.

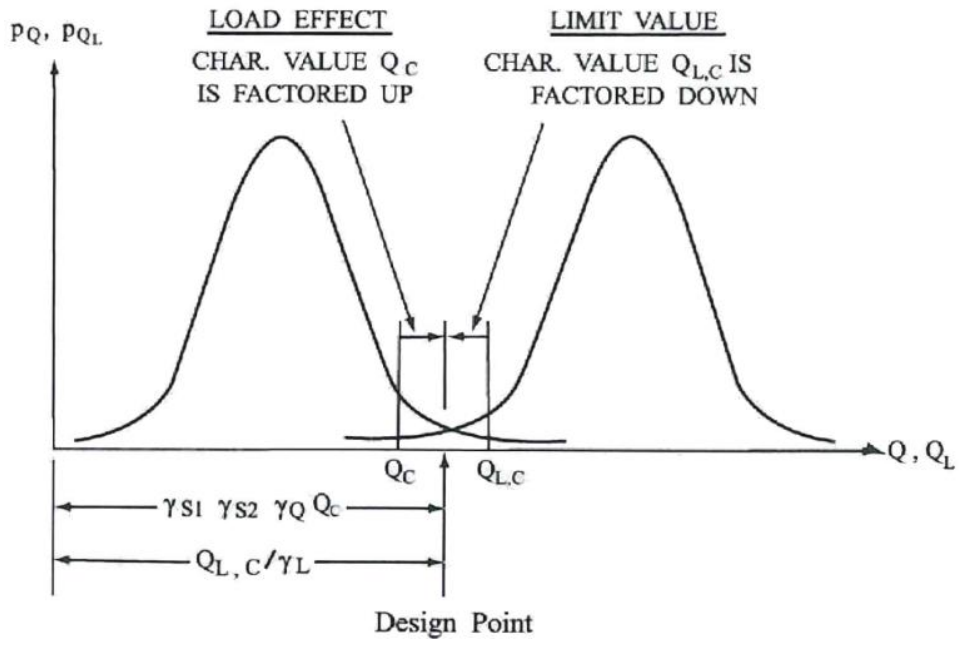

Fig. 11. Use of partial safety factors (Hughes and Paik 2013)

\subsection{Ultimate limit states of stiffened panels}

In structural design, the most important constraints are the strength criteria, which are set to ensure adequate safety and serviceability. All of the structural members must be able to clearly and explicitly meet the required degree-of-strength constraints. In the developed procedure, the strength constraints for stiffened panels are based on the ultimate limit state design technology, which is more useful for design and safety assessment than the current industry practices (Paik and Thayamballi, 2006). 
The ALPS/ULSAP method, integrated into the MAESTRO, is used to evaluate the ultimate limit strength of the stiffened panels. This method examines the primary modes of collapse for a stiffened panel under combined in-plane and lateral pressure loads. The possible collapse modes of a stiffened panel can be categorized into the six types, as indicated in Table 3 (Paik and Thayamballi 2003, Hughes and Paik 2013).

Table 3. Limit state failure modes

\begin{tabular}{|c|c|c|}
\hline & Description & Figure \\
\hline Mode I & Overall collapse after overall buckling & \\
\hline Mode II & $\begin{array}{l}\text { Collapse of the plating between stiffeners, } \\
\text { without the failure of stiffeners }\end{array}$ & \\
\hline Mode III & $\begin{array}{l}\text { Beam-column type collapse of a stiffener } \\
\text { with attached plating }\end{array}$ & \\
\hline Mode IV & $\begin{array}{l}\text { Local buckling of stiffener web } \\
\text { (after buckling collapse of the attached plating) }\end{array}$ & \\
\hline Mode V & $\begin{array}{l}\text { Lateral-torsional buckling (tripping) } \\
\text { of a stiffener }\end{array}$ & \\
\hline Mode VI & Gross yielding & \\
\hline
\end{tabular}

The mode III collapse pattern is the most common failure pattern in a stiffened panel. The structural limit state capacity and the demand are defined as follows:

$$
\begin{gathered}
C_{d}=\frac{C_{k}}{\gamma_{D}} \\
D_{d}=\gamma_{D} D_{k}
\end{gathered}
$$

where $C_{k}$ and $D_{k}$ are the characteristic values of capacity and demand, respectively, and $\gamma_{C}$ and $\gamma_{D}$ are the partial safety factors associated with the uncertainties of capacity and demand, respectively. The measure of structural adequacy $(\eta)$ is defined as follows: 


$$
\eta=\frac{C_{d}}{D_{d}}
$$

To ensure safety, $\eta$ must be greater than 1 . Each of these requirements constitutes a constraint on the stiffened panel design. The structure safety measure $\eta$ can be normalized as an adequacy parameter, which is defined as follows:

$$
g=\frac{1-1 / \eta}{1+1 / \eta}
$$

As a result of the form of equation and the definition of safety measure $\eta$, the adequacy parameter $g$ ranges in value between \pm 1 . Specifically, $g \rightarrow 1$ as $\eta \rightarrow \infty$, either due to very small loads or very large limit values. At other extreme, $g \rightarrow 1$ as $\eta \rightarrow 0$, either as a result of a very large load, or a very small limit value. An optimal design is found when $g$ is close to 0 .

\subsection{Ultimate limit states of hull girders}

In terms of hull girder strength, the ultimate strength evaluations are quantified by the modified Paik-Mansour method, and integrated into MAESTRO in the optimization process. The collapse strength is quantified by ALPS/HULL, which is integrated into MAESTRO after the optimization process is complete.

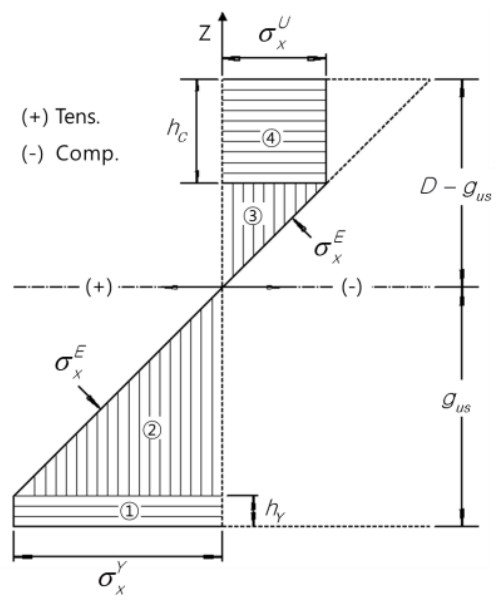

(a) Sagging

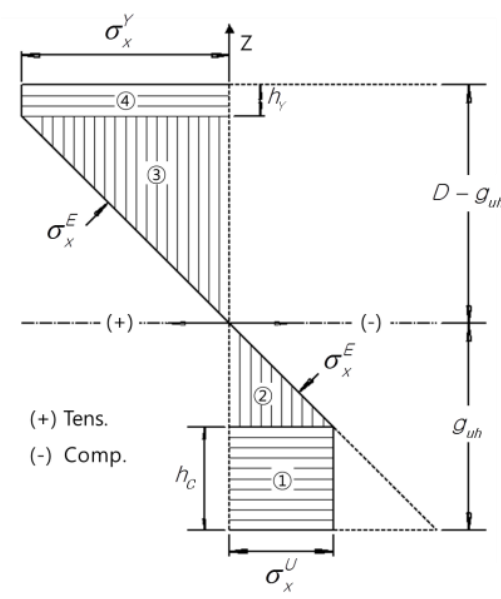

(b) Hogging 
Fig. 12. Modification of the Paik-Mansour presumption of the bending stress distribution across the cross-section of a ship's hull at the ultimate limit state, under sagging or hogging conditions (Paik et al. 2013).

Paik and Mansour (1995) suggest the original method for determining the bending stress distribution over the hull cross-section at the ultimate limit state under sagging or hogging conditions. This method is therefore named the Paik-Mansour method. The method is an accurate and efficient means of computing ultimate hull girder strength for ship structural design. The original Paik-Mansour method is modified to permit the expansion of the yielding part. Therefore, the modified Paik-Mansour method (Paik et al., 2012), as shown in Figure 12, is able to accommodate a pure vertical bending moment condition. Such accommodation is to be achieved regardless of the geometrical properties of the hull cross sections or of the vertical bending loading direction. In the optimization process, the ultimate strength evaluations are quantified for hull girders by the modified Paik-Mansour method.

To calculate the hull girder collapse strength after the optimization process is completed, the ALPS/HULL software (which is developed to conduct collapse analysis of a ship's hull under a combined hull girder load) is applied for quantification after the optimization process is completed. This software is also adopted for convenience on the on-bay sliced hull model, as shown in Figure 13.

The ALPS/HULL is based on the theory of the intelligent method that the super-size element itself takes care of the nonlinear structural behavior, which is called the intelligent super-size finite element method (Hughes and Paik 2013, Magoga and Flockhart 2013). The concept of ISFEM is suggested as a means to resolve the issues caused by the enormous computational effort required by the conventional nonlinear finite element method. ISFEM theory can use the same framework as the conventional nonlinear finite element method, and can readily take account of the interacting effects of local failures of individual structural components and the overall failure of the system structure. In the analysis of potential hull collapse using ISFEM, the supersize finite elements are taken into account, and the geometrical and material nonlinearities take care of the nonlinear structural behavior. 


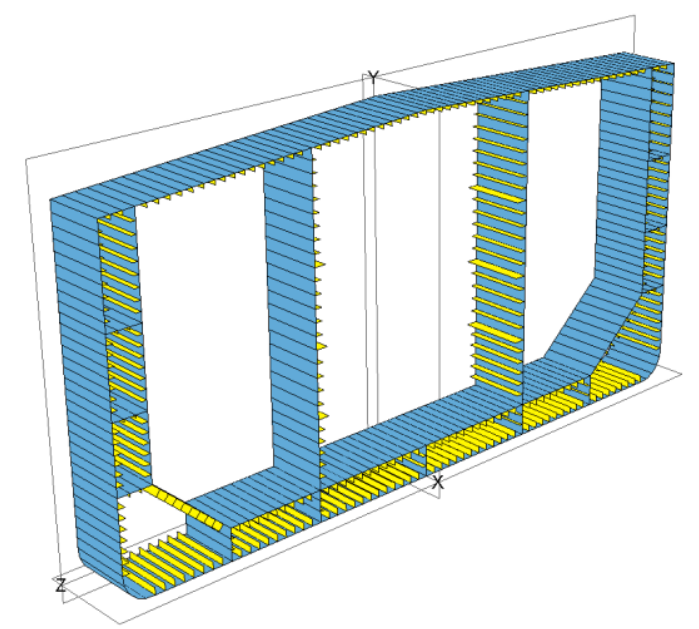

Fig. 13. ALPS/HULL ISFEM model of a one-bay sliced hull between the transverse frames

\section{Optimization Scheme for Multi-Objective Functions}

For structural optimization of the structural members, the first task is to identify the evaluation panels, which are the subjects of the ultimate strength evaluation, and the design clusters that are used to facilitate the structural manufacture process. Evaluation panels are collections of finite elements, which can be evaluated for their ultimate strength by using semianalytical methods. The design cluster is any group of panels or grillages for which uniform design variables are desired, and for which the scantlings of plate panels and stiffeners are all uniform.

To make the structural update more practical and to get better panel stress results, the evaluation panels are grouped as a collection of design clusters. MAESTRO automatically creates the evaluation panels, and it collects panel geometry and stress data for stiffened panels by using limit state evaluation. Thereafter, design clusters can be designated as any kind of practical groups. Figure 14 shows an example of evaluation panels and design clusters for double hull oil tankers. 


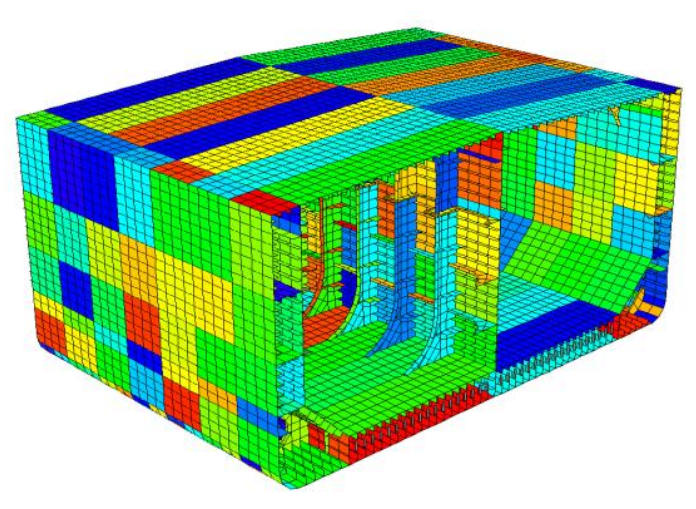

(a) Evaluation panels

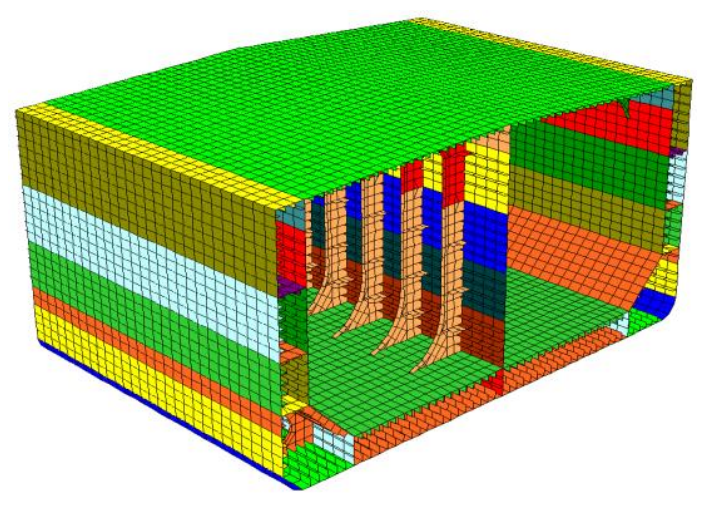

(b) Design clusters

Fig. 14. An example of evaluation panels and design clusters (Ma et al., 2013)

The multi-objective functions-based optimization for the design clusters becomes an iterative process. The first step of the iteration is to perform the ultimate strength evaluation, using ALPS/ULSAP for the plate panels and support members, and using the modified Paik-Mansour for the hull girders. The panel loads and the structural responses are obtained by load effect analysis. After evaluation, each stiffened panel is judged by the defined strength criteria.

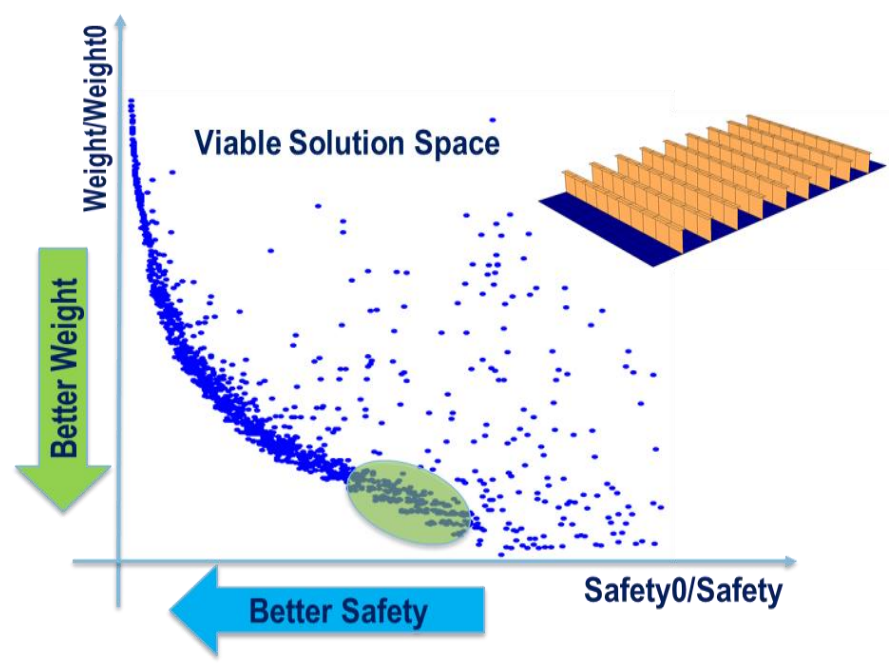

Fig. 15. An example of a Pareto optimal frontier of a stiffened panel, when $N_{x}=9$ (Ma et al., 2013)

The second step is to optimize each stiffened panel, using multi-objective optimization methods. The selected objective functions involved with design variables can find the 
appropriate solutions of a limit state-based ship's structural optimization by using the simulated annealing algorithm, as proposed by Ma, Hughes and Paik. Multi-objective simulated annealing (MOSA) gives rise to a set of optimal solutions instead of one optimal solution. Instead of using just one candidate for the final solution, MOSA uses a complete set of Pareto optimal solutions for a stiffened panel (Ulungu et al. 1999, Ma et al. 2013). Figure 15 shows an example of the complete set of Pareto optimal solutions for a stiffened panel.

The third step is the multi-objective optimization, for the global optimization of the entire structure. The applied loads for the stiffened panels and hull girders are often assumed to be constant throughout the design iterations. However, to fully optimize a group of stiffened panels, the applied load can no longer be assumed constant. The loads of each evaluation panel are functions of the scantlings of design clusters. As the scantlings of design clusters get updated in each perturbation, the corresponding panel loads are also changed. The overall iterative process for multi-objective functions-based optimization is illustrated in Figure 16, as based on the procedure developed in Chapter 2. The safety margin can be evaluated after the structural optimization is completed (Alfred Mohammed et al. 2016). In the present study, the modified Paik-Mansour formula method is used to optimize design variables as per the ultimate hull girder strength while the safety margin is evaluated using the ALPS/HULL progressive hull collapse analysis after the optimization process is completed. 


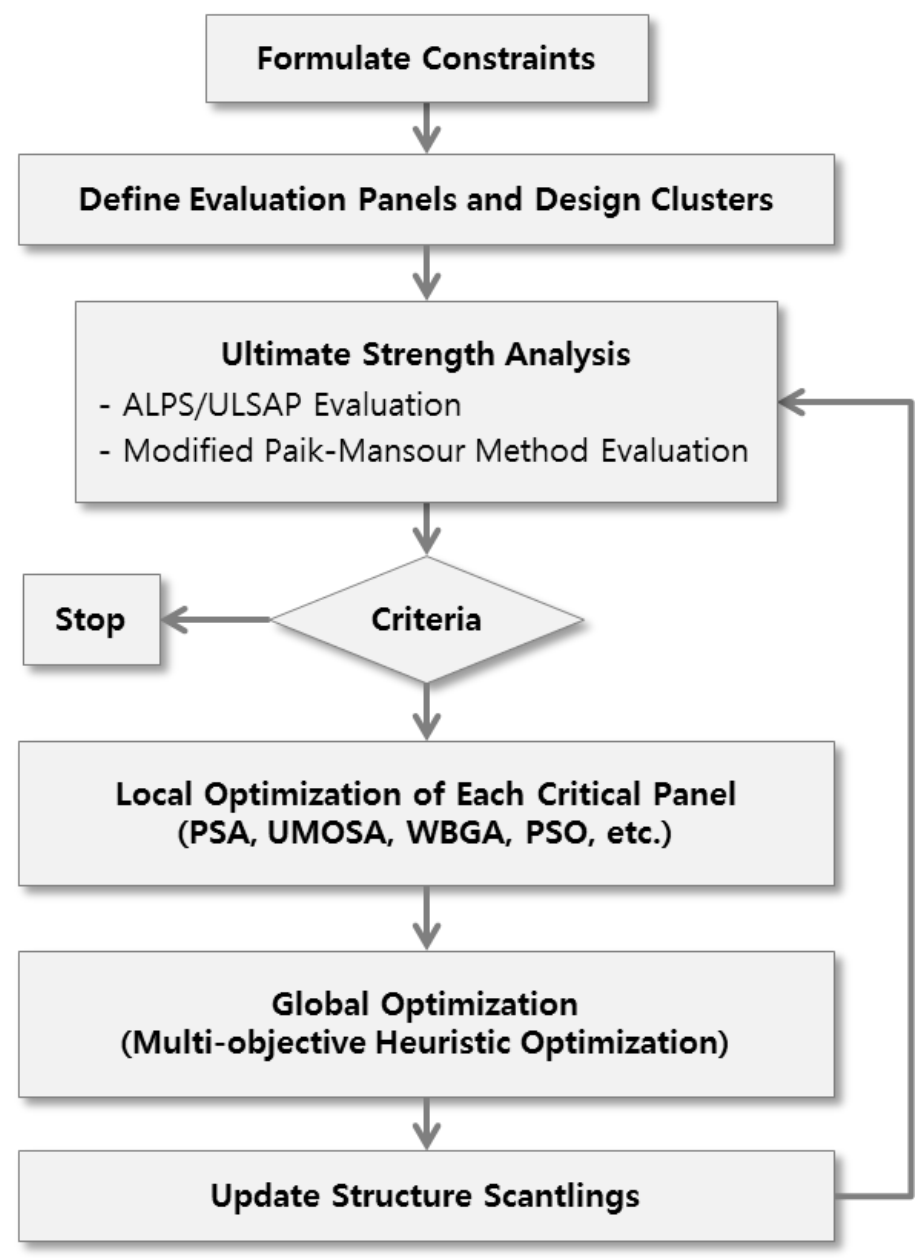

Fig. 16. The detailed iterative procedure of the multi-objective optimization, as based on the developed procedure

\section{Applied Example: Assessment of a VLCC-Class Double Hull Oil Tanker}

\subsection{Target ship - VLCC-class double hull oil tanker}

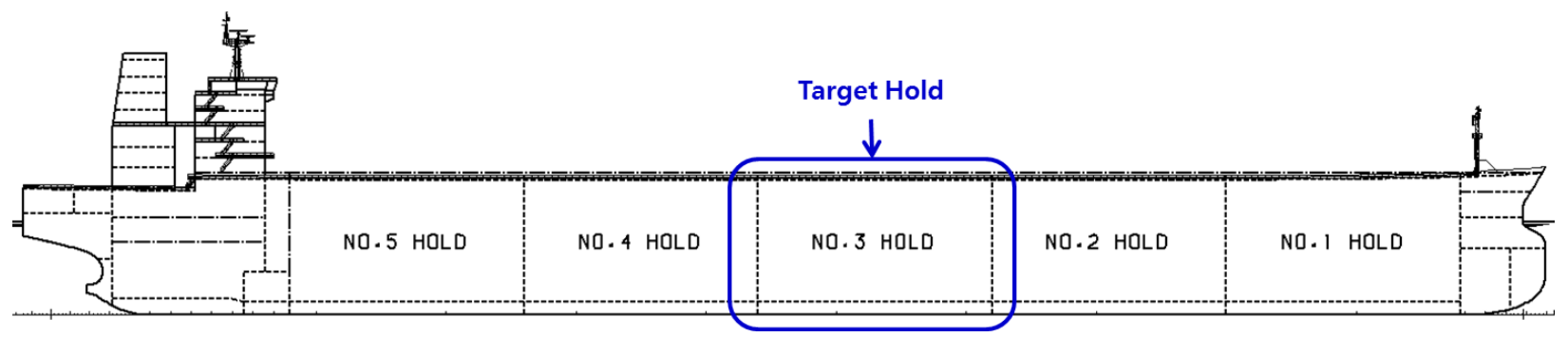

Fig. 17. General arrangement of the targeted hold (Profile view) 
The developed methodology is applied to the preliminary hull structural design of a VLCCclass double hull oil tanker. This ship consists of five cargo tanks, and a mid-ship cargo tank, the no. 3 hold, is selected as the target hold, as shown in Figure 17. This ship's main particulars are given in Table 4, and mid-section structural profile is as shown in Figure 18. The one cargo hold of 51.21 meters has 3 separated cargo tanks with 2 oil-tight longitudinal bulkheads and 8 web frames, with a cross-tie arrangement in the center cargo tanks.

Table 4. Main particulars of the VLCC-class double hull oil tanker

\begin{tabular}{|c|c|}
\hline Deadweight & 300,000 tons \\
\hline Length between perpendiculars & $320 \mathrm{~m}$ \\
\hline Breadth & $60.0 \mathrm{~m}$ \\
\hline Depth & $29.4 \mathrm{~m}$ \\
\hline Scantling draught & $21.6 \mathrm{~m}$ \\
\hline Block coefficient & 0.810 \\
\hline
\end{tabular}

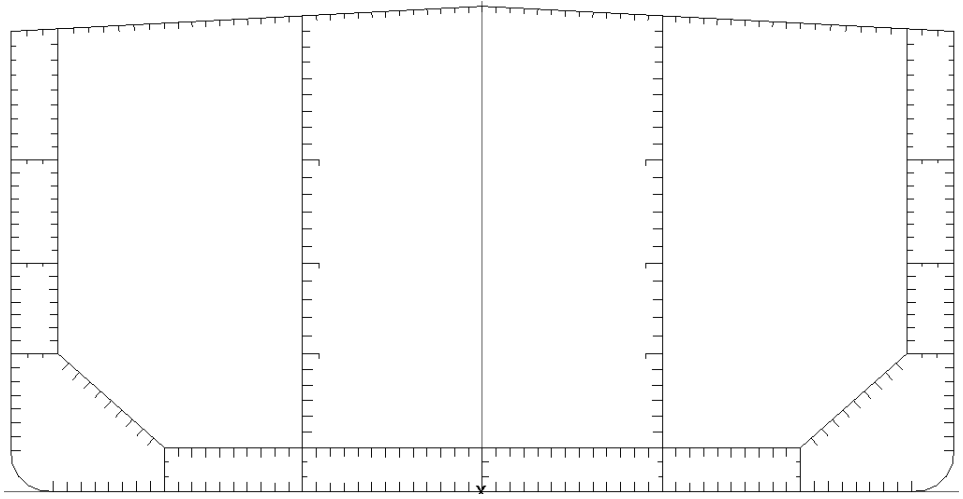

Fig. 18. Mid-section structural profile of the targeted hold

\subsection{Design optimization procedure}

Finite element modeling for the mid-ship cargo hold of the VLCC is performed using the Nastran based software, SeaTrust-Holdan (KR 2014), which is directly imported into the MAESTRO software without any modification, including all of the boundary and loading conditions for structural optimization, as shown in Figure 7.

In this application, the scantlings of plate panels and stiffeners are selected as the design variables. It is also possible to select design variables for the scantlings of the primary support 
members and the spacing of the stiffeners and primary support members. However, these features are excluded for comparison with the as-built reference ship under the same conditions.

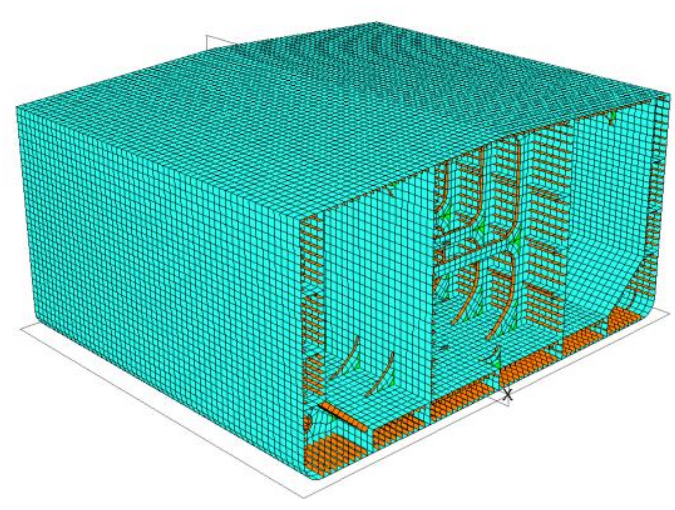

(a) All members of the mid hold

Fig. 19. Selected members for evaluation

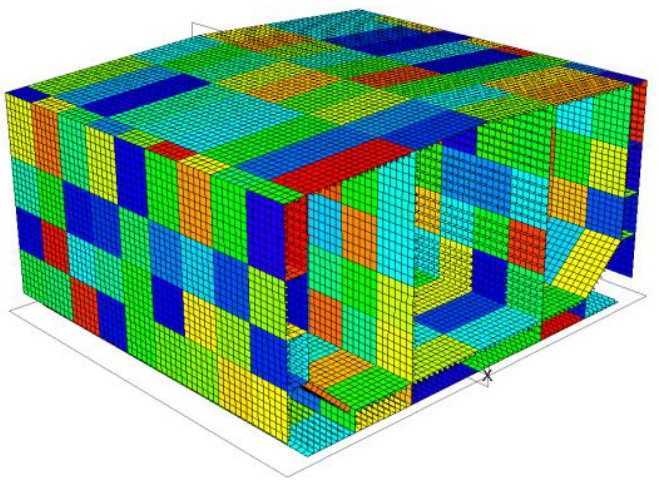

(a) Evaluation panels

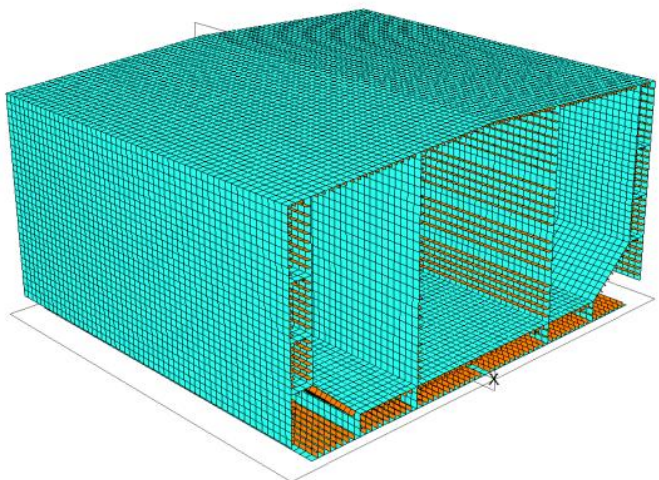

(b) Evaluation members

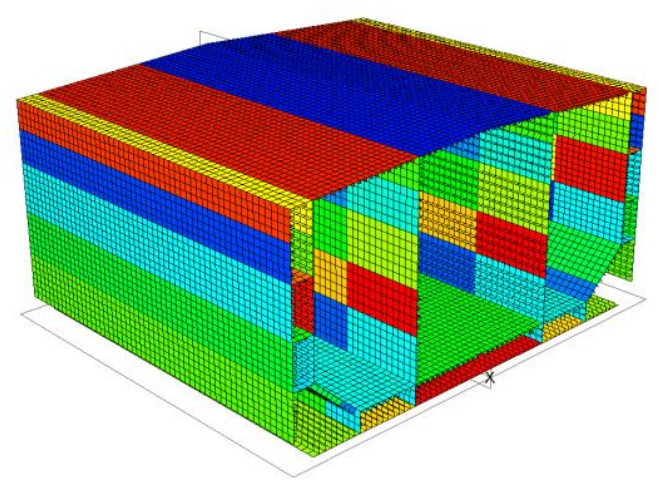

(b) Design clusters

Fig. 20. Selected evaluation members and evaluation patches (Level-1)

To optimize the structural scantlings, evaluation members are selected mainly from longitudinal members of the mid-hold, as shown in Figure 19. These members are subdivided into design clusters, as shown in Figure 14. It is noted that the bilge plate is not included in the optimization process although it is usually regarded as a longitudinal strength member. This is because the size of the bilge plate is rather determined based on other criteria for stability of the ship. 
The safety factors for collapse and serviceability are all 1.0, and the values of the upper and lower bound constraints for each manufacture group are applied, according to the limitations of the variable conditions such as the minimum requirements of CSR and the dimensions of the steel, as shown in Table 5.

Table 5. Upper- and lower-bound constraints for each evaluation member

\begin{tabular}{|c|c|c|c|c|c|c|}
\hline & \multirow{2}{*}{ Position } & \multirow{2}{*}{$\begin{array}{l}\text { Plate } \\
(\mathbf{m m})\end{array}$} & \multicolumn{4}{|c|}{ Stiffener (mm) } \\
\hline & & & Web Height & Web Thick. & Flange Width & Flange Thick. \\
\hline 1 & Upper Deck Region & $18.5-40$ & \multirow{7}{*}{$300-650$} & \multirow{7}{*}{$12-40$} & \multirow{7}{*}{$200-300$} & \multirow{7}{*}{$12-40$} \\
\hline 2 & Lower Bottom Region & $18.0-40$ & & & & \\
\hline 3 & Hopper 1 & $20.0-40$ & & & & \\
\hline 4 & Hopper 2 & $19.0-40$ & & & & \\
\hline 5 & S. Shell & $20.5-40$ & & & & \\
\hline 6 & Inner L/BHD & $15.5-40$ & & & & \\
\hline 7 & D/B Girder & $17.0-40$ & & & & \\
\hline 8 & STR & $12.0-40$ & $200-650$ & $12-40$ & $100-300$ & $12-40$ \\
\hline
\end{tabular}




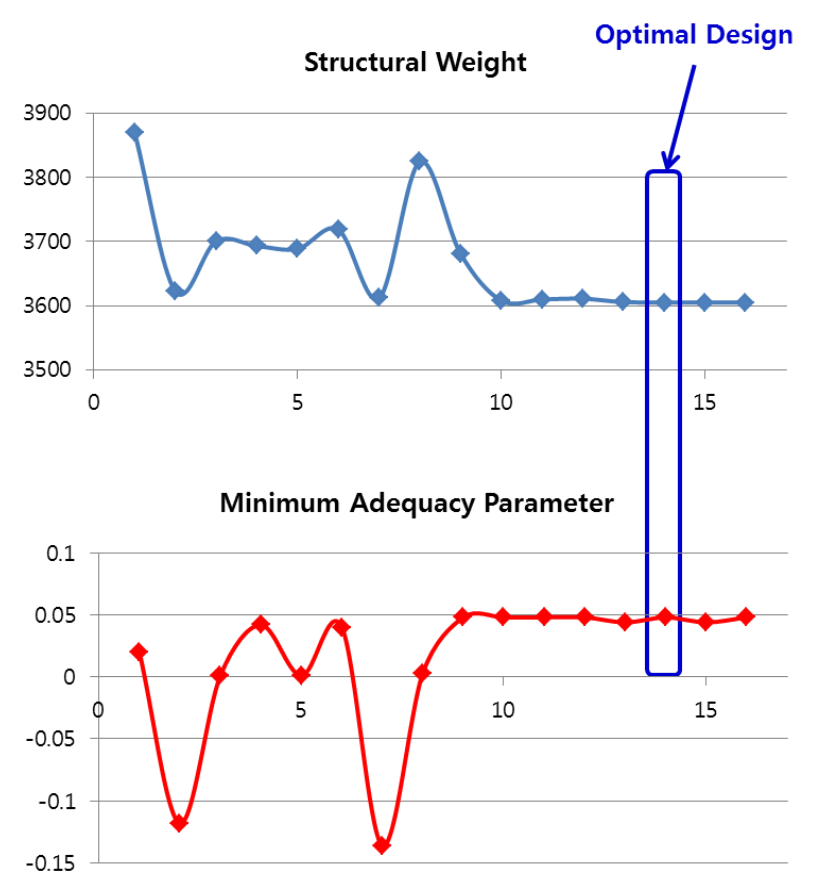

Fig. 21. History of the optimization process

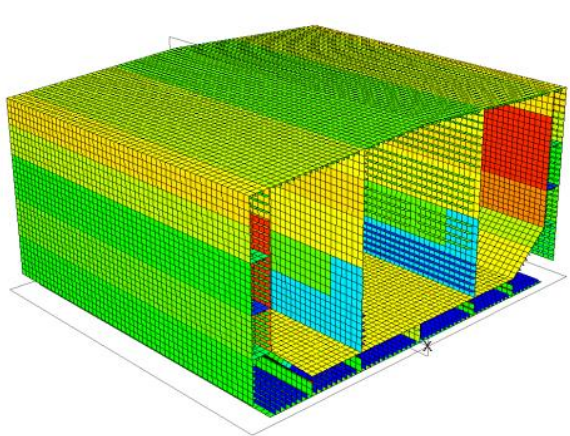

(a) Before optimization

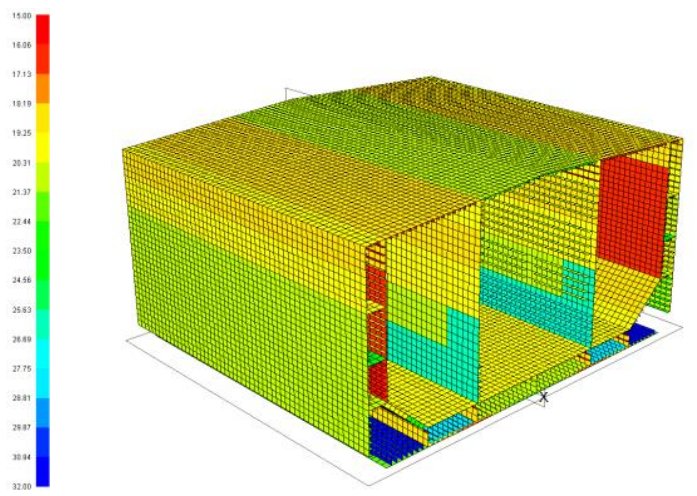

(b) After optimization

Fig. 22. The optimized scantlings of all of the evaluation members

In the next step, the optimization of the structural designs is performed by ALPS/ULSAP analysis, using MAESTRO for the ultimate strength evaluation, and by using the modified PaikMansour method for the hull girders. During the optimization process, the target model is converged in 16 design cycles in the course of a total of 25 design cycles, and this process is stopped when there is no weight improvement in the next 5 design cycles. Figure 21 shows the design history and the comparisons of structural weight and the minimum adequacy parameter 
for 16 design cycles. The original model is automatically updated according to the results of the optimized scantlings of all evaluation members, as shown in Figure 22.

After the the optimization is completed, the hull girder collapse strength evaluations are calculated by the ALPS/HULL software, using the on-bay sliced hull model made with the optimized scantling, as shown in Figure 23.

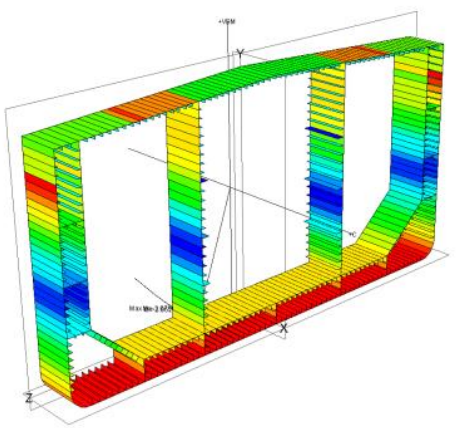

(a) Sagging

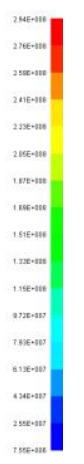

Fig. 23. Hull girder collapse strength of the optimized design, using ALPS/HULL

In the final step, the result of the optimization-based design is evaluated by verification against the acceptable criteria, in accordance with CSR by using SeaTrust-Holdan and PULS (DNV, 2006). The strength constraints, i.e., the maximum von Mises stress and the utilization factor against buckling for stiffened panels, do not exceed the acceptable criteria, as is shown in Figures 24 and 25.
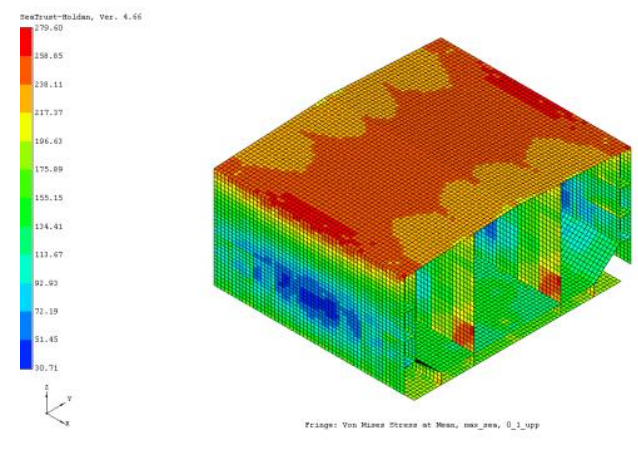

(a) Maximum von-Mises stress
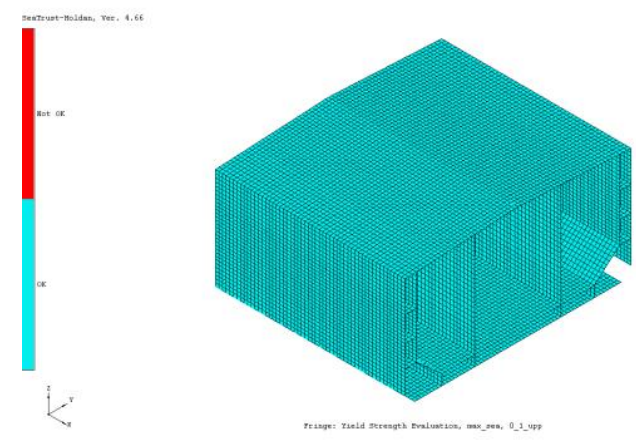

(b) Yield strength evaluation

Fig. 24. Yield strength evaluation, based on CSR requirements 


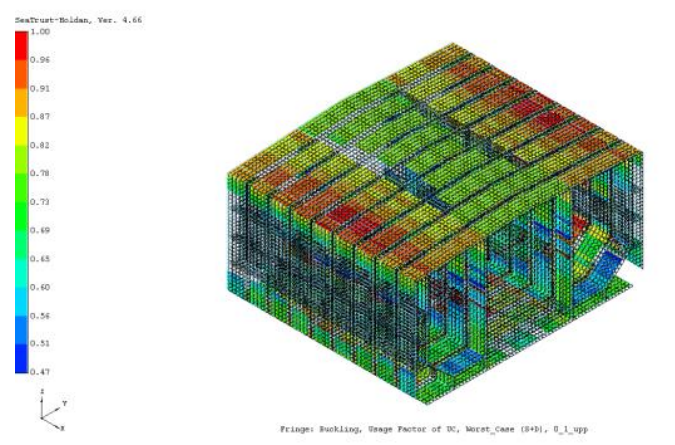

(a) Buckling usage factor

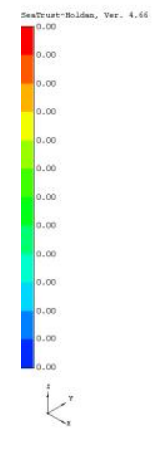

(b) Buckling failure

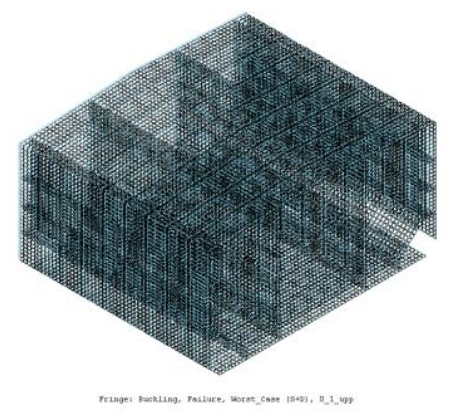

Fig. 25. Buckling strength evaluation, based on CSR requirements

\subsection{Design optimization results}

The evaluation members of the as-built reference ship originally weigh about 5,900 tons, on the basis of evaluating one cargo hold with a $3 \%$ structural safety margin. After the full optimization for structural designs with the alternative scantlings, as shown in Figure 18, the one cargo hold achieves savings in weight of about 176 tons, and the safety measure for the weakest member improves from 3\% to 5\%, as shown in Figure 26.

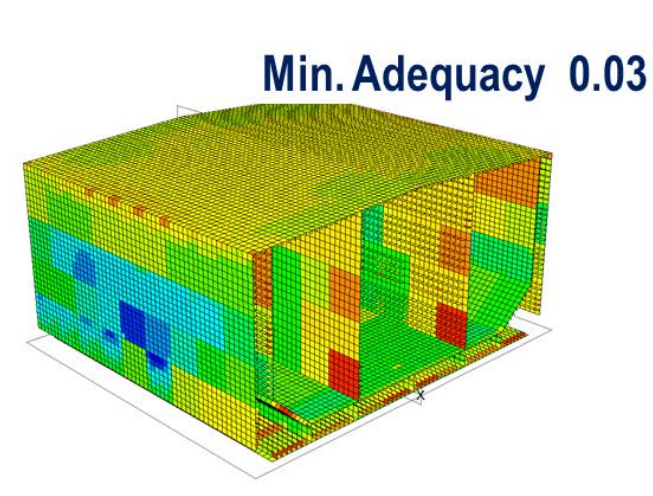

(a) Before optimization
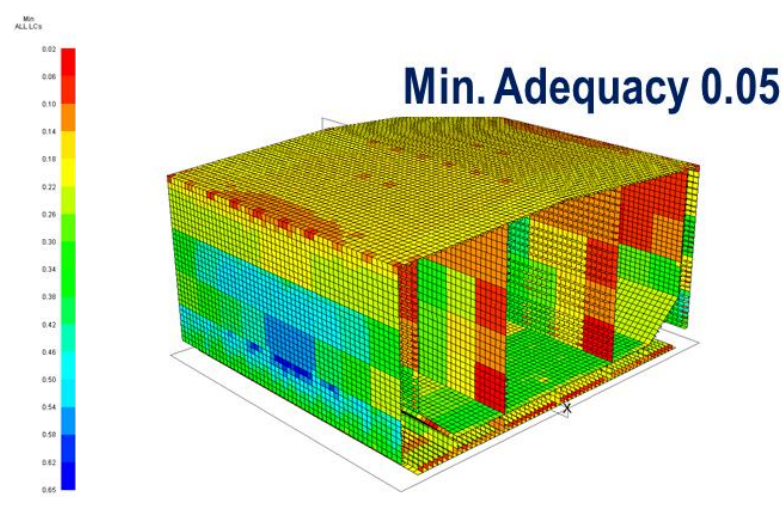

(b) After optimization

Fig. 26. Comparison of the minimum adequacy parameters for all evaluation members 


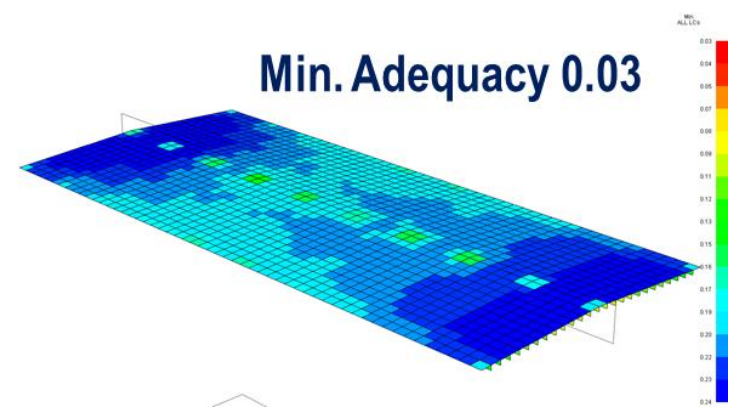

(a) Before optimization of the center tank

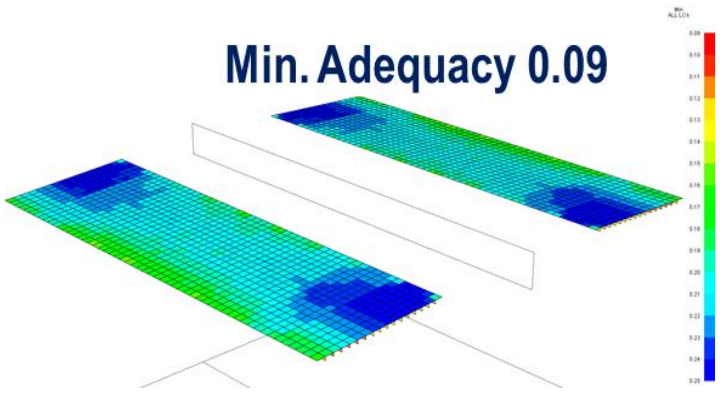

(c) Before optimization of the side tank

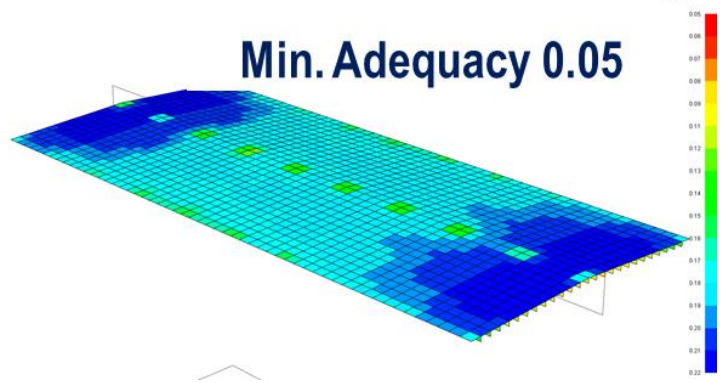

(b) After optimization of the center tank

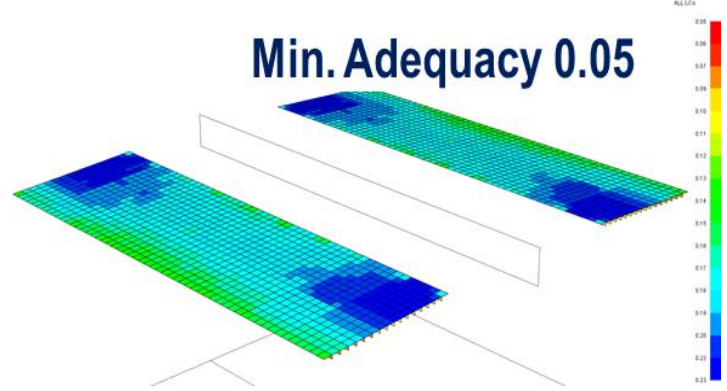

(d) After optimization of the side tank

Fig. 27. Comparison of the minimum adequacy parameters for features on the upper deck

Although the evaluation members are enhanced overall by $2 \%$, some of weak parts, such as the upper deck of the center tank and its bottom are relatively improved. Some of the excessive parts, such as upper deck of the side tank and the inner longitudinal bulkhead, are reduced in terms of their structural safety margins, as shown in Figure 27.

\subsection{Discussion}

The optimized structural designs definitely show positive results in terms of objective functions compared with the results from the as-built reference ship.

The structural weight is lightened by $3 \%$, or about 880 tons, based on the entire cargo hold, and the safety factors of critical members are increased from $3 \%$ to $5 \%$. The automated full optimization procedure reduces the man-hours required by $20 \%$, or about 100 man-hours, according to the required run-time of the finite element analysis and the qualitative decrease in design errors introduced by manual labor. Table 6 shows the quantitative design results compared with those of the as-built reference ship. 
Table 6. Comparison of design results with the practiced and the developed procedures

\begin{tabular}{|c|c|c|c|}
\hline Item & Before & After & Improvement \\
\hline Weight of 1 cargo hold & 5,889 tons & 5,713 tons & 176 tons savings \\
\hline $\begin{array}{c}\text { Weight of entire cargo hold } \\
(5 \text { cargo holds })\end{array}$ & 29,445 tons & 28,565 tons & 880 tons savings \\
\hline $\begin{array}{c}\text { Safety margin } \\
\text { for weakest member }\end{array}$ & $3 \%$ & $5 \%$ & $2 \%$ safety increment \\
\hline $\begin{array}{c}\text { Man-hours } \\
\text { for structural design }\end{array}$ & $500 \mathrm{M} / \mathrm{H}$ & $400 \mathrm{M} / \mathrm{H}$ & $20 \%$ man-hour reduction \\
\hline
\end{tabular}

\section{Concluding Remarks}

In this paper, a full optimization procedure for the structural design of merchant cargo ships is developed, and is shown to yield many benefits. Multiple objectives can be met with this procedure. Specifically, the minimization of structural weight and the maximization of structural safety can be achieved simultaneously. Due to the automated structural scantling process, considerable reductions can be achieved in the time required for design and in labor costs. These improvements can enable increased productivity, and can reduce the number of errors made in the complicated design stage.

In the developed optimization process, ultimate strength is evaluated by ALPS/ULSAP for the plate panels and support members, and by the modified Paik-Mansour method for the hull girders. The progressive hull girder collapse strength is evaluated by ALPS/HULL to confirm the adequacy of the hull girder collapse strength based safety, after the optimization process is completed. The completed optimization results are also checked, based on the design rules (i.e., the classification society rules) to attain design approval.

In terms of finite element modeling, the developed procedure can be applied in two optional ways. The first option is to perform the structural optimization for an entire ship hull structure at once. The second option is to adopt a process similar to the current industry practice, of using three cargo hold models, but with the full optimization of all design variables at the same time, even though only one cargo hold structure is optimized in each design stage. 
The developed procedure is then applied to an as-built VLCC-class double hull oil tanker, and a comparison is made between the developed design and the as-built reference ship. The results confirm the benefits of the developed procedure in terms of structural weight savings, structural safety improvements, and savings in man-hour costs. These results also show that the optimized structural designs from the applied developed procedure achieve a $20 \%$ reduction in man-hours, and a $3 \%$ reduction in structural weight. At the same time, the safety factors of critical members are significantly increased.

\section{Acknowledgements}

This study was undertaken at the Lloyd's Register Foundation Research Centre of Excellence at Pusan National University, Busan, Korea. Lloyd's Register Foundation (LRF), a UK registered charity and sole shareholder of Lloyd's Register Group Ltd, invests in science, engineering and technology for public benefit, worldwide.

\section{References}

Alfred Mohammed E, Benson SD, Hirdaris SE and Dow RS. 2016. Design safety margin through ultimate hull girder load combination analysis. Marine Structures, 46, pp. 78 - 101.

ALPS/HULL. 2016. A computer program for progressive collapse analysis of ship hulls, Stevensville, MD: Advanced Technology Center, DRS C3 Systems, Inc. Available online at http:// www.maestromarine.com.

ALPS/ULSAP. 2016. Ultimate limit state assessment of plate panels, Stevensville, MD: Advanced Technology Center, DRS C3 Systems, Inc. Available online at http:// WwW.maestromarine.com.

Czyzak P and Jaszkiewicz A 1998. Pareto simulated annealing - A metaheuristic technique for multiple objective combinatorial optimization, Journal of Multi-Criteria Decision Analysis, Vol.7, 34-47. 
Deb K, Agrawal S, Pratab A and Meyarivan T. 2000. A fast elitist non-dominated sorting genetic algorithm for multi-objective optimization: NSGA II. KanGAL Report No. 200001, Indian Institute of Technology, Kanpur, India.

DNV PULS. 2006. User's manual (version 2.06), Technical report no. 2004-0406. Det Norske Veritas, Oslo.

Hughes OF. 1983. Ship structural design: A rationally based, computer-aided, optimization approach. 1st ed., John Wiley \& Sons, New York.

Hughes OF and Paik JK. 2013. Ship structural analysis and design. The Society of Naval Architects and Marine Engineers, Alexandria, USA.

Hwang CL and Yoon KP. 1981. Multiple attribute decision making: Methods and applications. Springer-Verlag, Berlin.

IACS. 2012. Common structural rules for double hull oil tankers. International Association of Classification Societies, London.

Jin Y and Sendhoff B. 2008. Pareto-based multiobjective machine learning: An overview and case studies, IEEE Transaction on Systems, Man, and Cybernetics - Part V: Applications and Reviews, Vol.38, Bo.3, pp.397-415.

KR SeaTrust-Holdan. 2014. User's manual (version 4.66). Research and Development Center, Korean Register of Shipping, Busan, Korea.

Laumanns M. and Ocenasek J. 2002. Bayesian optimization algorithms for multi-objective optimization, Proceedings of $7^{\text {th }}$ International Conference on Parallel Problem Solving from Nature, Springer-Verlag London, UK, pp.298-307 (ISBN: 3-540-44139-5).

Man M and Hughes OF. 2011. Permanent means of access structural design using multiobjective optimization, Proceedings of the ASME $201130^{\text {th }}$ International Conference on Ocean, Offshore and Arctic Engineering, OMAE2011-49259, June 19-24, 2011, Rotterdam, The Netherlands. 
Ma M, Hughes OF and Paik JK. 2013. Ultimate strength based stiffened panel design using multi-objective optimization methods and its application to ship structures. Proceedings of the PRADS2013, Changwon, Korea.

Ma M, Paik JK and McNatt T. 2016. Hierarchically decomposed multi-level optimization for ship structural design, Proceedings of the ASME $201635^{\text {th }}$ International Conference on Ocean, Offshore and Arctic Engineering, OMAE2016-54452, June 19-24, 2016, Busan, Korea.

Ma M, Zhao C and Hughes OF. 2014. A practical method to apply hull girder sectional loads to full-ship 3D finite-element models using quadratic programming. Ships and Offshore Structures, $9: 3,257-265$.

Magoga T and Flockhart C. 2013. Effect of weld-induced imperfections on the ultimate strength of an aluminum patrol boat determined by the ISFEM rapid assessment method, Ships and Offshore Structures, 9(2): 218-235.

MAESTRO Version 11.3. 2016. Program documentation. Advanced Marine Technology Center, DRS Technologies Inc. Available online at http://www.maestromarine.com.

McNatt T, Ma M and Hunter S. 2013. Historical perspective on the structural design of special ships and the evolution of structural design methods. Ships and Offshore Structures, 8:3-4, 404414.

Na SS and Karr DG. 2013. An efficient stiffness method for the optimum design of ship structures based on common structural rules. Ships and Offshore Structures, 8:1, 29-44.

OCTOPUS. 2012. Octopus-designer and Octopus-analyzer manuals. Faculty of Mechanical Engineering and Naval Architecture. University of Zagreb, Zagreb (Croatia).

Paik JK, Kim DK, Park DH, Kim HB, Mansour AE and Caldwell JB. 2012. Modified PaikMansour formula for ultimate strength calculations of ship hulls. Ships and Offshore Structures, $8: 3-4,245-260$.

Paik JK and Mansour AE. 1995. A simple formulation for predicting the ultimate strength of ships. Journal of Marine Science Technology. 1:1, 52-62. 
Paik JK and Thayamballi AK. 2003. Ultimate limit state design of steel-plated structure. John Wiley \& Sons, Chichester, UK.

Paik JK and Thayamballi AK. 2006. Some recent developments on ultimate limit state design technology for ships and offshore structures. Ships and Offshore Structures, 1:2, 99-116.

Payer HG and Schellin TE. 2013. A class society's view on rationally based ship structural design. Ships and Offshore Structures, 8:3-4, 319-336.

Pedersen K, Messer M, Allen JK and Mistree F. 2013. Hierarchical product platform design: A domain-independent approach. Ships and Offshore Structures, 8:3-4, 367-382.

Roh MI and Lee KY. 2006. Development of a 3D CAD system for modelling hull structure at the initial ship design stage. Ships and Offshore Structures, 1:2, 135-151.

Shin SH, Song HC and Jang CD. 2006. Optimum structural design of tankers using multiobjective optimization technique. Ships and Offshore Structures, 1:3, 213-219.

Subin, K.K., Das, P.K., Quigley, J. and Hirdaris, S.E. (2012) Risk analysis of damaged ships - A data driven Bayesian approach. Ships and Offshore Structures, 7(3), pp. 333-347.

Turkmen BS and Turan O. 2007. A new integrated multi-objective optimization algorithm and its application to ship design. Ships and Offshore Structures, 2:1, 21-37.

Ulungu LE, Teghem J, Fortemps PH and Tuyttens D. 1999. MOSA method: A tool for solving multiobjective combinatorial optimization problems. Journal of Multi-Criteria Decision Analysis, 8,221 .

Yang HZ, Chen JF, Lu QJ and Ma N. 2014. Application of knowledge-based engineering for ship optimisation design. Ships and Offshore Structures, 9:1, 64-73.

Zanic V. 2013. Methods and concepts for the multi-criteria synthesis of ship structures. Ships and Offshore Structures, 8:3-4, 225-244.

Zanic V, Andric J and Prebeg P. 2013. Design synthesis of complex ship structures. Ships and Offshore Structures, 8:3-4, 383-403. 


\section{Appendix: Pareto Simulated Annealing Algorithm}

1. Select a starting sample of solution set $S$. For each solution vector $x \in S$, update the nondominated set $M$ with $x$.

2. For each solution $x \in S$, generate a random solution $y$. If $y$ is not dominated by $x$, then update the set $M$ with $y$.

3. Select a non-dominated solution $x^{\prime}$, from set $S$ closest to $x$. If there exists no such $x^{\prime}$ or it is the first iteration with $x$, then set random weights such that: $\sum_{j=1} \lambda_{j}=1$, else dynamically scale weights for each objective function $z_{j}$ :

$\lambda_{j}= \begin{cases}\beta \lambda_{j}^{x} & z_{j}(x) \geq z_{j}\left(x^{\prime}\right) \\ \frac{\lambda_{j}^{x}}{\beta} & z_{j}(x)<z_{j}\left(x^{\prime}\right)\end{cases}$

where $\beta$ is constant and greater than 1 . Normalize the weight such that $\sum_{j=1} \lambda_{j}=1$.

4. Update $x$ with $y$ with acceptance probability $P\left(x, y, T, \wedge^{x}\right)$. If the solution $y$ is accepted, make it the current solution and update the non-dominated set $M$. If the solution is not accepted, retain the earlier solution $x$ as a current solution.

5. Reduce the temperature according to annealing schedule. Repeat steps 2 to 5 . 